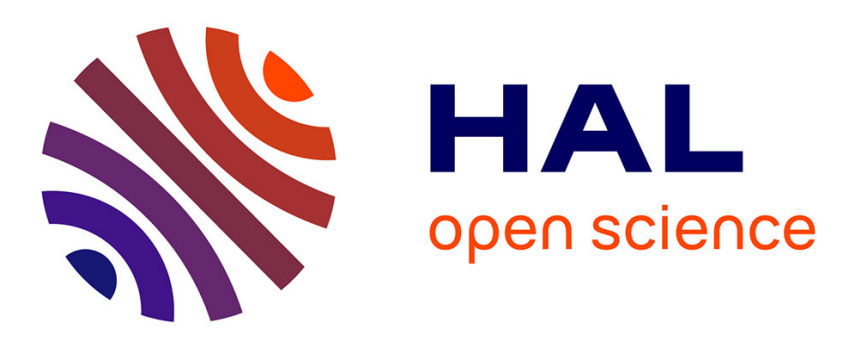

\title{
Numerical investigations of the free surface effect in three-dimensional polycrystalline aggregates
}

Yoann Guilhem, Stéphanie Basseville, Francois Curtit, Jean-Michel Stephan, Georges Cailletaud

\section{- To cite this version:}

Yoann Guilhem, Stéphanie Basseville, Francois Curtit, Jean-Michel Stephan, Georges Cailletaud. Numerical investigations of the free surface effect in three-dimensional polycrystalline aggregates. Computational Materials Science, 2013, 70, pp.150-162. 10.1016/j.commatsci.2012.11.052 . hal01017647

\section{HAL Id: hal-01017647 https://hal.science/hal-01017647}

Submitted on 2 Jul 2014

HAL is a multi-disciplinary open access archive for the deposit and dissemination of scientific research documents, whether they are published or not. The documents may come from teaching and research institutions in France or abroad, or from public or private research centers.
L'archive ouverte pluridisciplinaire HAL, est destinée au dépôt et à la diffusion de documents scientifiques de niveau recherche, publiés ou non, émanant des établissements d'enseignement et de recherche français ou étrangers, des laboratoires publics ou privés. 


\title{
Numerical investigations of the free surface effect in three-dimensional polycrystalline aggregates
}

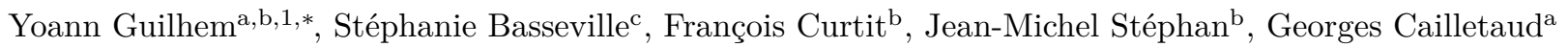 \\ ${ }^{a}$ MINES ParisTech, Centre des Matériaux, CNRS UMR 7633, BP 87, 91003 Evry Cedex, France \\ ${ }^{b}$ EDF R\&D, Département Matériaux et Mécanique des Composants, Avenue des Renardières, 77818 Moret-sur-Loing Cedex, France \\ ${ }^{c}$ LISV, Université de Versailles Saint-Quentin, 45 avenue des Etats-Unis, 78000 Versailles, France
}

\begin{abstract}
The aim of the present paper is to investigate the consequences of the loading on the free surface response in polycrystalline aggregates. The study is made on a 316L stainless steel. Finite element computations using a crystal plasticity model are performed to simulate a polycrystalline aggregate submitted to different cyclic loadings. A statistical analysis of the results is carried out to extract information concerning the local stress and local strain fields at the free surface. The analysis of plastic strain localization on surface maps and inside the bulk through transparent volumetric views allows to exhibit the effects of the grain orientation and of the loading on local mechanical fields. The computation of an indicator characterizing extrusion/intrusion steps give some information on the initiation sites.
\end{abstract}

Keywords: Polycrystal, Crystal plasticity, Finite Element Analysis, Fatigue, Surface relief

\section{Introduction}

Fatigue crack initiation can be studied at several scales. For engineers working at a macroscale, initiation means that one of the microcracks becomes large enough to be seen as a macroscopic crack, the propagation of which is no longer influenced by the local texture: This occurs for a crack length of several grains. In material science, fatigue crack nucleation is rather related to crack lengths close to the grain size. Under High Cycle Fatigue conditions, the initiation period may represent between one half and $90 \%$ of the component life. Since the micropropagation is affected by the local grain microstructure, this is the main source of the scatter that is classically found in this domain. The so called "Microstructurally Short Cracks (MSCs)" and the different stages of initiation and micropropagation have been described in a well known paper [1. Microstructural features such as grain boundaries and crystallographic orientations play an important role in this process.

Nevertheless, the different stages of fatigue cracks initiation and propagation were defined earlier [2]. According to his work, initiation is mainly due to Persistent Slip

*Corresponding author. Present address: ESRF, 6 rue Jules Horowitz, BP 220, 38043 Grenoble Cedex 9, France, Tel.: +33-4$76-88-21-16$

Email addresses: yoann.guilhem@esrf.fr (Yoann Guilhem), stephanie.basseville@uvsq.fr (Stéphanie Basseville),

francois.curtit@edf.fr (François Curtit)

jean-michel.stephan@edf.fr (Jean-Michel Stéphan),

georges.cailletaud@mines-paristech.fr (Georges Cailletaud)

${ }^{1}$ Present affiliation: Université de Lyon, INSA-Lyon, MATEIS

CNRS UMR 5510, 69621 Villeurbanne, France
Bands (PSBs), the presence of which can be explained by means of a physical model introducing dislocation motions [3]. Observations of fatigued copper single crystals allow to understand the formation of intrusion-extrusion steps at the free surface, also called Persistent Slip Markings (PSMs), which leads to the initiation of a surface microcrack [4. Blochwitz et al. 5] measured PSM appearing at the surface of a nickel polycrystal under cyclic loading. Further observations about fatigue induced surface relief were carried out by Man et al. on 316L Stainless Steel using Atomic Force Microscope [6]. This work showed that extrusion steps height increases significantly during the early fatigue cycles before developing with a three times slower growth rate, proportional to the number of cycles $N$. Discrete Dislocation Dynamics simulations showed that the extrusion height remains proportional to $\sqrt{N}$ in the case of symmetric cyclic loading, while it is linearly related to $N$ in the presence of a positive mean strain [7. This statement is consistent with the fact that fatigue life decreases for a given stress amplitude, when a mean stress is applied. Being aware of these experimental observations, reproducing these surface steps and predicting their growth with a numerical model is a key point for a better prediction of fatigue crack initiation.

Recent studies compared 2D FE simulations and experimentally observed plastic strain localization [8] or slip traces [9]. Some of the numerical studies were focused on the effect of free surface but without introducing crystal plasticity [10. First investigations on surface effect in 3D polycrystalline aggregates were presented in [11, but only monotonic loadings were considered and only a few orientation configurations were investigated. Statistical analy- 
ses, based on multiple microstructure configurations, were conducted to look into the origin of the scatter observed in the results under HCF conditions [12].

The aim of this paper is to study the free surface effect in polycrystalline aggregate, using Finite Element Crystal Plasticity (FECP). This implies to get accurate information about both plastic strain localization and its spatial organization on the surface and inside the bulk. That is why 3D computations have been performed. A crystal plasticity model with non linear kinematic hardening is introduced in a 3D mesh which conforms grain boundaries. The free surface response is studied for a series of loading paths with a quick overview of the mesh sensitivity. A statistical study is performed to characterize the influence of the neighborhood on the local mechanical fields.

The paper is organized as follows. In the first part, the constitutive equations, the material parameter identification, the FE mesh and the applied boundary conditions are described. Next, several statistical analyses are performed to characterize:

i The distribution of local variables depending on the mesh density.

ii The von Mises stress and the cumulated viscoplastic slip for various classes of grains (all grains, surface grains, core grains and BC grains).

iii The influence of crystallographic orientation and grain boundary misorientation on a grain behavior.

Finally, we focus on the localization of different variables such as cumulated viscoplastic slip, von Mises plastic strain and intrusion/extrusion steps that are candidate fatigue indicators.

\section{Numerical model}

\subsection{Constitutive equations}

Méric-Cailletaud's crystal plasticity model is used, in the framework of the finite element code ZeBuLoN [13. Small strain assumption is used, which seems reasonable, since, in our past experience, the amount of rotation of a slip plane is around $1^{\circ}$ for $1 \%$ macroscopic strain. Under cyclic loading, ratchetting may be present if the local loading path presents unbalanced stress components. However, as long as the loading conditions prevent mean stress or mean strain to appear, which is the case in our study, no ratchetting can occur, so small strains assumption reminds reasonable. Otherwise large strains modeling might be necessary to capture local lattice rotations. Each grain is assigned a randomly selected orientation and the displacement fields are supposed to be continuous at grain boundaries. Therefore, stress discontinuities can appear at these sites. Strain rate tensor is decomposed into an elastic and a viscoplastic part:

$$
\underset{\sim}{\dot{\varepsilon}}={\underset{\sim}{\dot{\varepsilon}}}^{e}+{\underset{\sim}{\dot{\varepsilon}}}^{p}={\underset{\approx}{C}}^{-1}: \underset{\sim}{\dot{\boldsymbol{\sigma}}}+{\underset{\sim}{\dot{\varepsilon}}}^{p}
$$

Cubic elasticity is defined by the fourth order tensor of elastic moduli $\underset{\approx}{C}$. Hence elasticity itself produces residual intergranular stresses.

The resolved shear stress $\tau^{s}$ is computed on each slip system $s$ by means of the orientation tensor $\underset{\sim}{\boldsymbol{m}}$ :

$$
\begin{aligned}
\tau^{s} & =\underset{\sim}{\boldsymbol{\sigma}}:{\underset{\sim}{\boldsymbol{m}}}^{s} \\
\text { with } \quad \underline{\boldsymbol{m}}^{s} & =\frac{1}{2}\left(\underline{\boldsymbol{l}}^{s} \otimes \underline{\boldsymbol{n}}^{s}+\underline{\boldsymbol{n}}^{s} \otimes \underline{\boldsymbol{l}}^{s}\right)
\end{aligned}
$$

where $\underline{\boldsymbol{n}}^{s}$ is the normal to the slip plane and $\underline{\boldsymbol{l}}^{s}$ is the slip direction.

The viscoplastic strain rate tensor is defined as the sum of the contributions of all the slip systems $s$. Each viscoplastic slip rate $\dot{\gamma}^{s}$ is given by a power law, function of the resolved shear stress, the initial critical resolved shear stress $\tau_{0}$ and two hardening variables, $x^{s}$ for kinematic hardening and $r^{s}$ for isotropic hardening.

$$
\begin{aligned}
& \stackrel{\dot{\varepsilon}}{\dot{\varepsilon}}^{p}=\sum_{s} \dot{\gamma}^{s}{\underset{\sim}{\sim}}^{s} \\
& \dot{\gamma}^{s}=\operatorname{sign}\left(\tau^{s}-x^{s}\right) \dot{v}^{s} \\
& \dot{v}^{s}=\left\langle\frac{\left|\tau^{s}-x^{s}\right|-r^{s}-\tau_{0}}{K}\right\rangle^{n}
\end{aligned}
$$

where $K$ and $n$ are the parameters which define viscosity, $\dot{\gamma}^{s}$ stands for slip rate, $v^{s}$ is the cumulated viscoplastic slip on slip system $s$. The operator $\langle$.$\rangle takes the positive part$ of its argument.

Hardening depends on two internal state variables, $\alpha^{s}$ for kinematic and $\rho^{s}$ for isotropic hardening, as described by equations (7) to (10). This framework offers a single set of active slip systems, and avoids complex procedures attached to the definition of slip activity for the time independent plastic case [14].

$$
\begin{gathered}
x^{s}=c \alpha^{s} \\
r^{s}=b Q \sum_{r} h_{s r} \rho^{r} \\
\dot{\alpha}^{s}=\left(\operatorname{sign}\left(\tau^{s}-x^{s}\right)-d \alpha^{s}\right) \dot{v}^{s} \\
\dot{\rho}^{s}=\left(1-b \rho^{s}\right) \dot{v}^{s}
\end{gathered}
$$

where $c$ and $d$ are material parameters for kinematic hardening, $Q$ and $b$ are material parameters for isotropic hardening. Self-hardening and latent hardening between different slip systems are characterized by means of the interaction matrix $h_{s r}$. The material of the study is an austenitic stainless steel, the crystallographic structure of which is FCC. Slip operates on octahedral slip systems (see figure 1), so that slip plane normals and directions are respectively $\left\{\begin{array}{lll}1 & 1 & 1\end{array}\right\}$ and $\left\langle\begin{array}{lll}1 & 1 & 0\end{array}\right\rangle$. The corresponding interaction matrix is defined by six coefficient $h_{i}$ [15].

\subsection{Material parameters identification}

The parameters of the cubic elasticity matrix for austenite are provided by Huntington [16], therefore no 


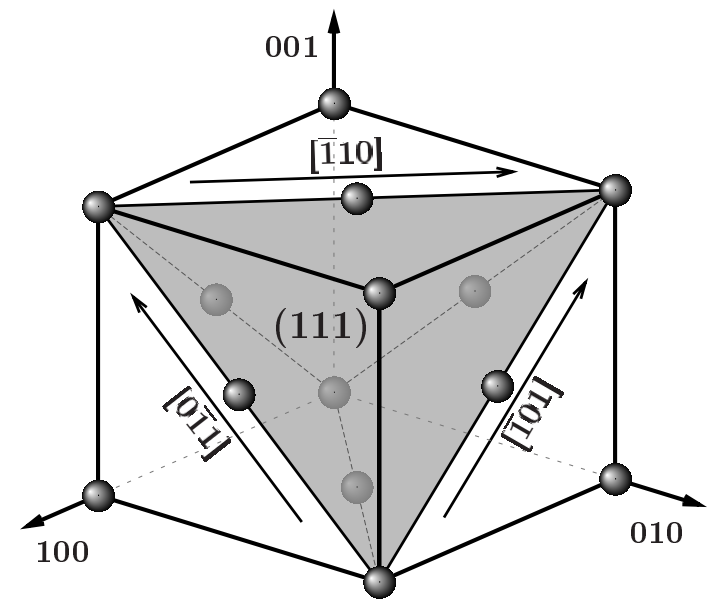

Figure 1: Octahedral slip systems in FCC crystal.

identification is required for these coefficients. The material parameters of the crystal plasticity model are identified from the macroscopic tensile curve, solving the inverse problem by means of a mean field model. Phases are characterized by classes of crystallographic orientations. The identification process introduces two steps, both of them based on the classical approach deriving from the problem of an inclusion in an infinite medium [17. The reference model in this domain is the self-consistent scheme due to Hill [18], that defines internal stresses by means the elastoplastic accommodation tensor $\underset{\approx}{\boldsymbol{L}}$, depending on the shape of inclusions.

$$
\dot{\sim}^{i}=\underset{\sim}{\dot{\boldsymbol{\Sigma}}}+\underset{\approx}{\boldsymbol{L}}:\left(\underset{\sim}{\dot{\boldsymbol{E}}}-{\underset{\sim}{\dot{\varepsilon}^{i}}}^{i}\right)
$$

where $\boldsymbol{\sigma}_{\sim}^{i}$ and $\underset{\sim}{\boldsymbol{\Sigma}}$ are respectively the local (for phase $i$ ) and macroscopic stress tensors, $\varepsilon^{i}$ is the strain tensor related to phase $i$ and $\underset{\sim}{\boldsymbol{E}}$ the macroscopic strain tensor.

In our case, Berveiller-Zaoui's model (BZ) is used instead. It can be deduced from Hill's model, for the special case of a monotonic loading path, uniform elasticity and spherical shape of the inclusions.

$$
\begin{gathered}
\boldsymbol{\sigma}_{\sim}^{i}=\underset{\sim}{\boldsymbol{\Sigma}}+2 \mu(1-\beta) \alpha\left({\underset{\sim}{\boldsymbol{E}}}^{p}-{\underset{\sim}{\boldsymbol{\varepsilon}}}^{p, i}\right) \\
\beta=\frac{2(4-5 \nu)}{15(1-\nu)} \\
\frac{1}{\alpha}=1+\frac{3 \mu E^{p}}{2 \Sigma}
\end{gathered}
$$

where $\mu$ is the macroscopic shear modulus and $\nu$ the Poisson's ratio. $E^{p}$ and $\Sigma$ are respectively the von Mises equivalent of the macroscopic plastic strain and of the stress tensor. During the deformation, $\alpha$ varies from 1 to 0 . This model does not need any additional parameter to define the scale transition rule. It can then be easily applied to calibrate the single crystal material parameters on the tensile test [19]. Since the model is valid for tensile tests only, the identification has then to be refined for cyclic tests. This is made by means of the $\beta$-scale transition rule [20, described by equations 15 to 19 , which is more accurate for cyclic and non-proportional loadings.

$$
\begin{aligned}
& \boldsymbol{\sigma}^{i}=\underset{\sim}{\boldsymbol{\Sigma}}+2 \mu(1-\beta)\left(\underset{\sim}{\boldsymbol{\beta}}-{\underset{\sim}{\boldsymbol{\beta}}}^{i}\right) \\
& \beta=\frac{2(4-5 \nu)}{15(1-\nu)} \\
& \underset{\sim}{\boldsymbol{\beta}}=\sum_{i} f_{i} \boldsymbol{\beta}_{\sim}^{i} \\
& \dot{\sim}^{i}={\underset{\sim}{\dot{\varepsilon}}}^{p, i}-D \varepsilon_{e q}^{p, i}{\underset{\sim}{\boldsymbol{\beta}^{i}}}^{i} \\
& \varepsilon_{e q}^{p, i}=\sqrt{\frac{2}{3} \sim^{\varepsilon^{p, i}}:{\underset{\sim}{\varepsilon}}^{p, i}}
\end{aligned}
$$

where $\boldsymbol{\beta}^{i}$ and $\boldsymbol{\beta}$ are respectively the local and average accommodation tensors, $f_{i}$ is the volume fraction of phase $i$, and $D$ is the parameter allowing to adjust the transition rule. The set of parameters originating from the application of BZ's model is used to initialize the identification process. This new step allows to identify the scale transition parameter $D$ and to refine the values of the single crystal model parameters. Both monotonic tensile and cyclic tests are taken into account in the process.

The experimental data base was provided by EDF [21]: Tensile and cyclic tests have been performed on a $316 \mathrm{~L}$ stainless steel. The mechanical steady state is assumed to be reached at the 10 th simulated cycle, $N_{\text {sta }}$, for each loading amplitude. The slip matrix coefficient $h_{i}$ have been chosen in agreement with recent studies which mention a strong latent hardening on collinear systems [22, 23]. The parameters obtained are presented in table 11. Figure 2 illustrates the good agreement between experiments and simulations for a tensile test and three strain controlled cyclic tests $\Delta \varepsilon / 2=0.2 \%, 0.3 \%$ and $0.5 \%$.

For a deformation greater than $0.2 \%$, the BZ simulation is in perfect agreement with experiment for the tensile test. The simulation performed with the $\beta$-model slightly overestimates the value for small strain and underestimates it for larger strains (see figure 2a), but the agreement is still acceptable. This degradation of the simulation is linked to the fact that a compromise must be made between monotonic and cyclic tests. The simulation of the latter is very satisfactory (figure $2 \mathrm{~b}$ to $2 \mathrm{~d}$ ). Since our study focuses on small strain ranges, the preference has been given to the $\Delta \varepsilon / 2=0.2 \%$ test in the calibration process.

Nevertheless, this identification still remains incomplete, as most of the numerical studies on polycrystals using CPFE. Indeed, our model calibration is based on fatigue tests at the macro-scale, transposed at the scale of the Representative Volume Element (RVE) of the polycrystal. To make this step more rigorous, one should use the same type of data from a polycrystal, but at the grain scale. This means getting stress-strain state of each grain within the polycrystal, at the surface and inside the bulk, with a non-destructive technique to let the possibility to provide data at different steps during loading and unload- 


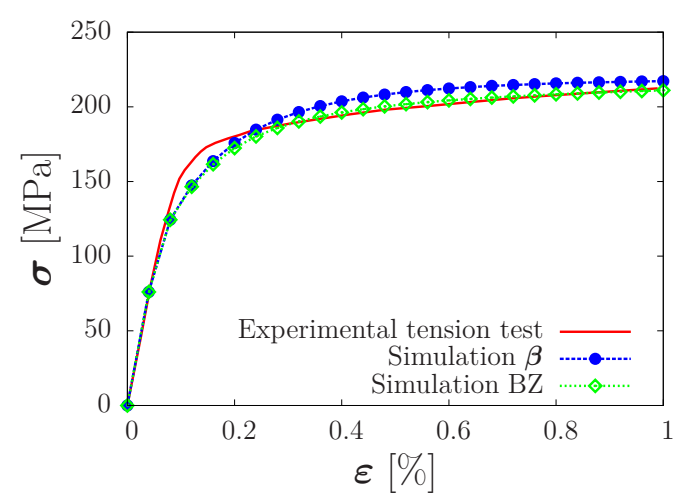

(a) Tensile test until $\varepsilon=1 \%$.

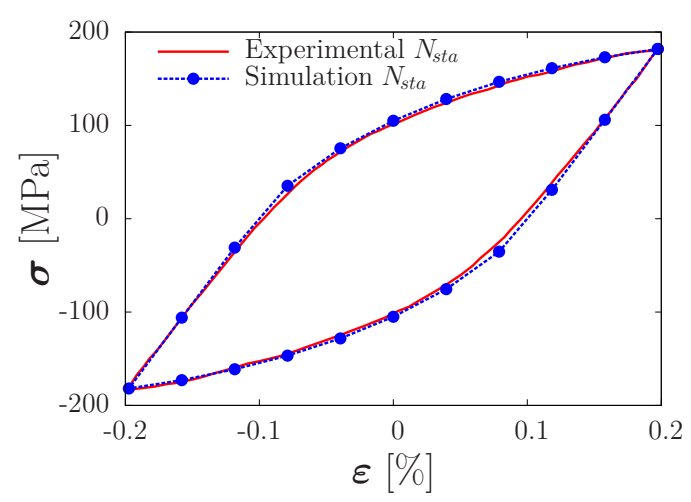

(b) Fatigue $\varepsilon= \pm 0.2 \%$.

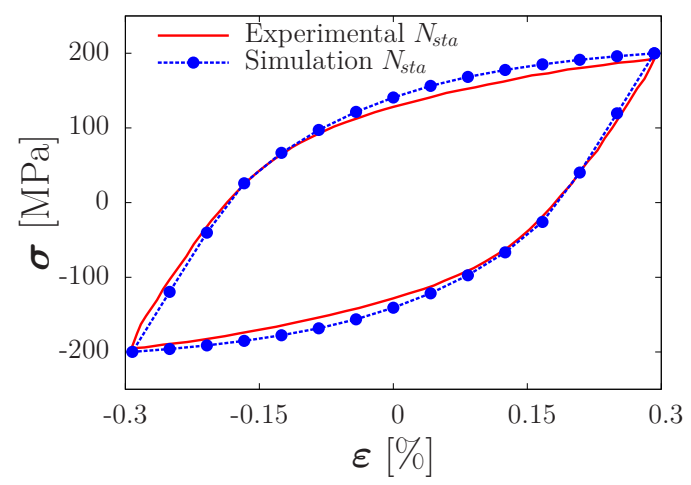

(c) Fatigue $\varepsilon= \pm 0.3 \%$.

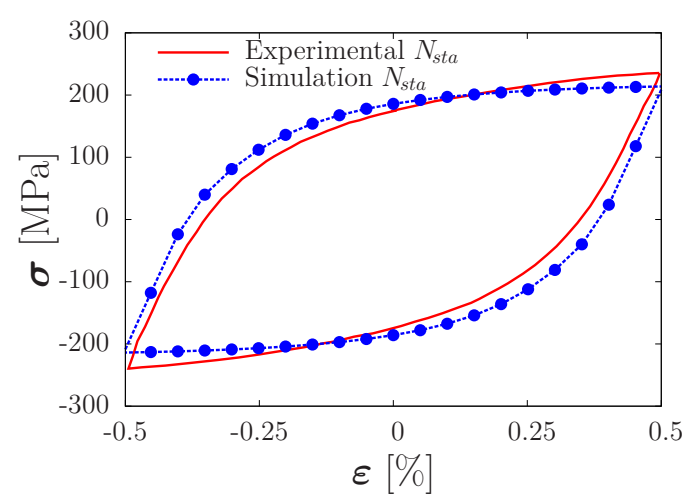

(d) Fatigue $\varepsilon= \pm 0.5 \%$.

Figure 2: Comparison between experimental and numerical results on tensile and cyclic tests.

\begin{tabular}{ll}
\hline \multicolumn{2}{c}{ Cubic elasticity } \\
\hline$C_{1111}$ & $197,000 \mathrm{MPa}$ \\
$C_{1122}$ & $125,000 \mathrm{MPa}$ \\
$C_{1212}$ & $122,000 \mathrm{MPa}$ \\
\hline \multicolumn{2}{c}{ Flow rule } \\
\hline$K$ & $12 \mathrm{MPa} . \mathrm{s}^{-\mathrm{n}}$ \\
$n$ & 11 \\
$\tau_{0}$ & $40 \mathrm{MPa}$ \\
\hline \multicolumn{2}{c}{ Isotropic hardening } \\
\hline$Q$ & $10 \mathrm{MPa}$ \\
$b$ & 3 \\
\hline Kinematic hardening \\
\hline$c$ & $40,000 \mathrm{MPa}$ \\
$d$ & $1,500 \mathrm{MPa}$ \\
\hline Slip interaction matrix \\
\hline$h_{1}$ & 1 \\
$h_{2}$ & 1 \\
$h_{3}$ & 0.6 \\
$h_{4}$ & 12.3 \\
$h_{5}$ & 1.6 \\
$h_{6}$ & 1.8 \\
\hline Scale transition model \\
\hline$E$ & $190,000 \mathrm{MPa}$ \\
$\nu$ & 0.3 \\
$\mu$ & $70,000 \mathrm{MPa}$ \\
$D$ & 192 \\
\hline &
\end{tabular}

Table 1: Material parameters identified for 316L Steel.

ing sequences. Thus, having access to the local stressstrain tensors on a real microstructure, i.e. grain shape and orientations, would give a better reference for the comparison with the crystal plasticity model. Such experimental data could be obtained using 3D synchrotron imaging techniques like Absorption Contrast Tomography and Diffraction Contrast Tomography (DCT) [24, 25]. Polycrystal samples made of a few hundred to a few thousand grains can be reconstructed into a voxelated volume and then converted into a mesh ready for Finite Element computations. As proposed by Oddershede et al. [26], it is also possible to use near-field and far-field DCT acquisitions of a polycrystalline specimen to determine the average of elastic strain tensors in each grains with a precision close to $10^{-4}$ without having to reconstruct the polycrystalline aggregate. As a second example, Reischig et al. based their strain tensor measurements on the reconstructed volume and the Friedel pairs [27, 28]. However these grain-resolved strain tensor measurement techniques are restricted to a certain class of materials and has not been tested on Stainless Steel right now. This might be introduced in future work.

\subsection{Mesh and boundary conditions}

The mesh, which global size is $250 \mu \mathrm{m} \times 250 \mu \mathrm{m} \times$ $125 \mu \mathrm{m}$, consists of 291 grains with an average size close to $50 \mu \mathrm{m}$. It is built by applying a Voronoi tessellation 


\begin{tabular}{lrrr} 
Mesh & Coarse & Medium & Fine \\
\hline Elements & 16,099 & 65,170 & 454,673 \\
Degrees of freedom & 70,497 & 277,530 & $1,880,697$ \\
Number of domains & 1 & 4 & 20 \\
CPU time [h] & 3 & 20 & 52
\end{tabular}

Table 2: Main features of the three meshes.

on a regular distribution of seeds, which generates truncated octahedron shaped grains. Creating a scatter on germ positions allows to get grains with homogeneous size and shape and to have various geometrical orientations for grain boundaries (see figure 3). Tetrahedral elements with quadratic interpolation are used, following [29]. Three mesh densities are used for our preliminary investigation (coarse, medium and fine) with respectively 23,499, 92,341 and 626,899 nodes. Mesh density is kept homogeneous inside the whole aggregate, without any mesh refinement near grain boundaries. Parallel computing is used for the two larger meshes, with a FETI domain decomposition technique 30]. Table 2 sums up the number of elements, nodes, resulting degrees of freedom, number of domains and CPU time for each mesh density. The loading applied in the computation considered in this table is the uniaxial-y, which corresponds to a cyclic deformation of $\pm 0.2 \%$ in $y$ direction. It will be described hereafter. The CPU time remains relatively high even for a large number of subdomains. As pointed out elsewhere [31, this could be improved by replacing the current linear solver (sparse direct) by a DSCPACK solver. It was not made here since our DSCPACK version does not detect the rigid body modes.

A tension-compression cyclic load is considered with a load ratio $R=-1$. Four kinds of cyclic loading are investigated; uniaxial in $x$ direction, uniaxial in $y$ direction, biaxial and biaxial with the same equivalent strain as uniaxial. In each case, symmetric boundary conditions are applied on the hidden faces (see figure 3) and face $\mathrm{Z}$ is a free surface. For each type of loading, the other boundary conditions are:

(a) Uniaxial-x

- Face $X$ : cyclic loading to obtain $E_{x x}= \pm 0.2 \%$.

- Face $Y$ : uniform normal displacement.

(b) Uniaxial-y

- Face $X$ : uniform normal displacement.

- Face $Y$ : cyclic loading to obtain $E_{y y}= \pm 0.2 \%$.

(c) Biaxial-eq

- Face $X$ : cyclic loading to obtain $E_{x x}= \pm 0.14 \%$.

- Face $Y$ : cyclic loading to obtain $E_{y y}= \pm 0.14 \%$.

(d) Biaxial

- Face $X$ : cyclic loading to obtain $E_{x x}= \pm 0.2 \%$.

- Face $Y$ : cyclic loading to obtain $E_{y y}= \pm 0.2 \%$.

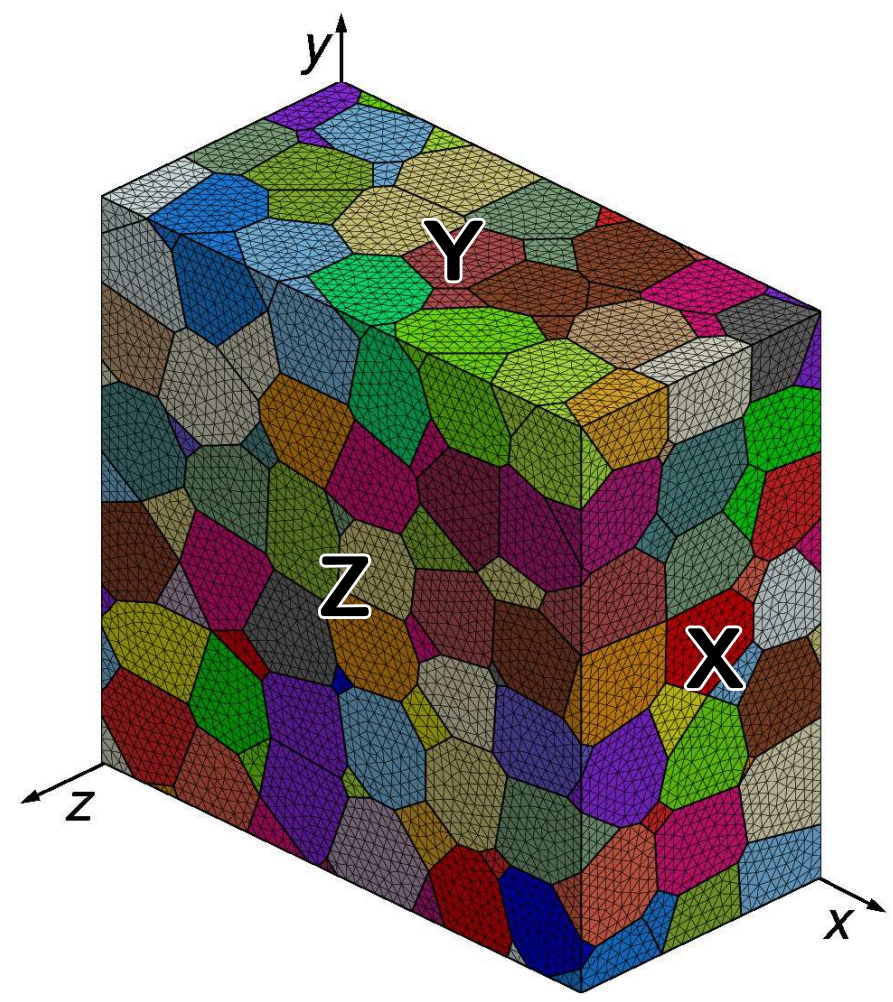

Figure 3: Polycrystalline aggregate made of 291 grains (fine mesh).

In cases (a) and (b), a multipoint constraint is applied to preserve a zero resulting force for the faces with an uniform normal displacement. That way, all faces stay flat during the whole computation except face $Z$, which is free. This is obviously not reproducing the realistic boundary conditions, where local stress deviation would change the displacement field to fit the deformation of adjacent grains. In our case, more constraint are added than with experimental 32 or periodic 22 boundary conditions. But, as explained later in the paper, the perturbation of the stress and strain fields, due to these MPC boundary conditions, vanishes after the first layer of grains.

\section{Results and discussion}

\subsection{Investigated parameters and variables}

In the following, the effect of crystal plasticity is characterized by three parameters, the influence of which will be analyzed on the stress and strain fields.

- $d_{\mathrm{GB}}$ : distance to the grain boundary, defined for each integration point.

- $M_{\max }$ : Schmid factor at the macroscale, defined for each grain.

This parameter is described by the equation.

$$
\begin{gathered}
M^{s}=\left(\underline{\boldsymbol{N}} \cdot \underline{\boldsymbol{n}}^{s}\right) \times\left(\underline{\boldsymbol{N}} \cdot \underline{\boldsymbol{l}}^{s}\right) \\
M_{\max }=\max _{s} M^{s}
\end{gathered}
$$


where the loading direction in $\underline{N}$ direction.

- $\Delta \theta_{w}^{i}$ : weighted misorientation of a grain with its adjacent grains. The misorientation $\Delta \theta^{i, j}$ between two adjacent grains $i$ and $j$, accounting for cubic crystal symmetry, is computed according to Randle 33. A $\mathrm{C}++$ routine detects adjacent grains and calculates the contact surface between the grains $i$ and $j$, written $S^{i, j}$. Then $\Delta \theta_{w}^{i}$ is computed by weighting each misorientation $\Delta \theta^{i, j}$ by $S^{i, j}$.

$$
\Delta \theta_{w}^{i}=\frac{1}{\sum_{j} S^{i, j}} \sum_{j} S^{i, j} \Delta \theta^{i, j}
$$

- $\theta_{\mathrm{GB} / \text { load }}:$ angle between the loading axis and the normal to the grain boundary plane.

The grain location inside the aggregate is another parameter that will be studied. Figure 4 shows the three classes of grains depending on their location: in contact with boundary conditions, inside the core or at the surface. A grain is considered as in contact with $\mathrm{BC}$ if at least one of his nodes is under displacement control in one of the BC. The surface grains have at least one node on the free surface, without being affected by one of the BC. Finally, the core grains are the remaining ones.

A series of variables will be post-processed from the FE results.

- $\sigma_{m i s e s}$, the equivalent von Mises stress, computed from the second invariant of deviatoric stress $\boldsymbol{s}$ by

$$
\sigma_{\text {mises }}=\sqrt{\frac{3}{2} s: \underset{\sim}{s}}
$$

- $\sum \gamma_{\text {cum }}$, the sum of cumulated viscoplastic slips on all the slip systems.

$$
\sum \gamma_{c u m}=\sum_{s} v^{s}
$$

- $\varepsilon_{m i s e s}^{p}$, the von Mises equivalent plastic strain:

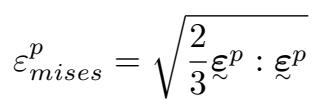

- $N_{\gamma}$, the number of active slip systems, defined by

$$
\dot{v}^{s}>\frac{1}{100} \max _{r} \dot{v}^{r} \quad \text { and } \quad \dot{v}^{s}>1 \times 10^{-4} \mathrm{~s}^{-1}
$$

- $\underline{\gamma}_{\text {surf }}$, the slip trace indicator or PSM indicator takes account of both local amount of plastic slip and the orientation of the glide with respect to the free surface normal. The projection on the free surface normal vector $\underline{\boldsymbol{n}}_{\text {surf }}$ of the plastic slip of each slip plane is calculated. This variable provides an estimation of the height of the steps (intrusion-extrusion phenomenon) that can be created at the surface. For all

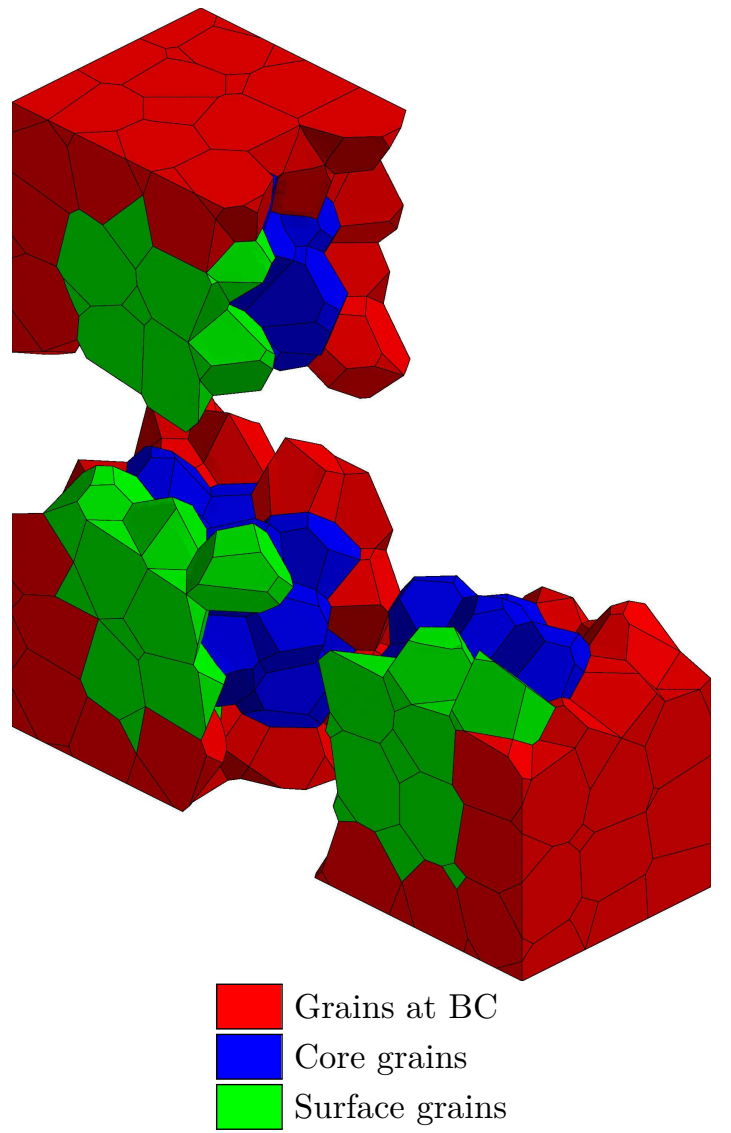

Figure 4: Exploded view of the aggregate mesh with a color code to exhibit the different types of grains: grains at BC, core grains and surface grains.

the slip planes $p$ and the associated slip systems $s$, the norm of this vector is:

$$
\gamma_{\text {surf }}^{p}=\left(\sum_{s \in p} \gamma^{s} \underline{\boldsymbol{l}}^{s}\right) \cdot \underline{\boldsymbol{n}}_{\mathrm{surf}}
$$

The maximum value of these contributions, written $\gamma_{\text {surf }}$, is stored with the associated surface trace orientation $\underline{\boldsymbol{l}}_{\text {surf }}$.

$$
\begin{gathered}
\gamma_{\text {surf }}=\max _{p}\left(\left|\gamma_{\text {surf }}^{p}\right|\right) \times \operatorname{sign}\left(\gamma_{\text {surf }}^{p}\right) \\
\underline{\boldsymbol{l}}_{\text {surf }}=\frac{\underline{\boldsymbol{n}}_{\text {surf }} \times \underline{\boldsymbol{n}}\left(\gamma_{\text {surf }}\right)}{\left|\underline{\boldsymbol{n}}_{\text {surf }} \times \underline{\boldsymbol{n}}\left(\gamma_{\text {surf }}\right)\right|} \\
\underline{\boldsymbol{\gamma}}_{\text {surf }}=\gamma_{\text {surf }} \underline{\boldsymbol{l}}_{\text {surf }}
\end{gathered}
$$

\subsection{Influence of the mesh density}

The choice of a relevant and reliable mesh density for polycrystalline aggregates remains a key problem in micromechanical Finite Element Analysis (FEA). It is shown in the following that meshes must have both high and homogeneous density. This is demonstrated on the uniaxial-y loading problem with the three meshes presented in section 2.3. All the computations are based on the same set of 291 orientations, and the distributions of the local variables in the whole aggregate are investigated on Gauss 


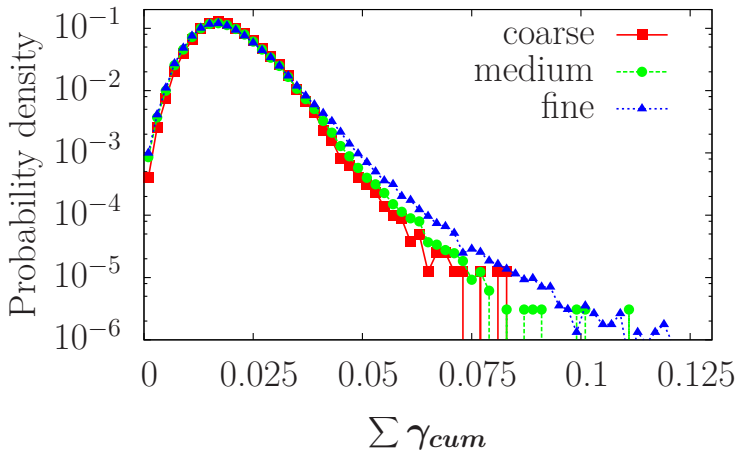

(a)

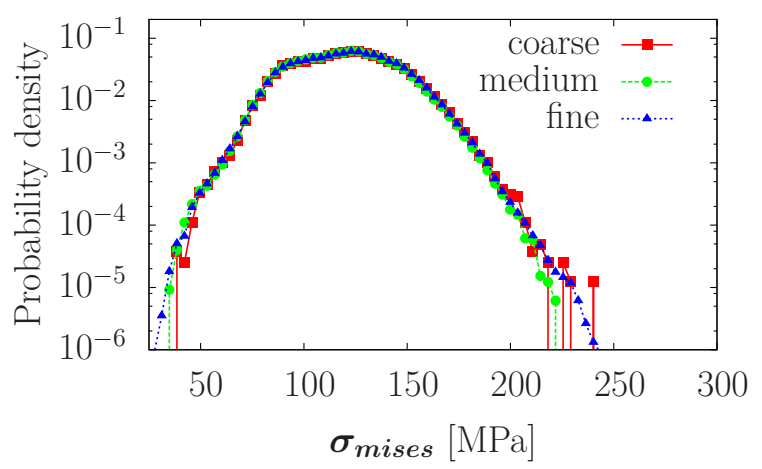

(b)

Figure 5: Local variables distributions Distribution (logarithmic scale) with different mesh densities.

points. These distributions and the related statistical parameters obtained with each of the three meshes are shown in figure 5 and in table 3. As a classical result, the finest mesh promotes local variables dispersion, especially in the case of plastic strain, without changing mean values.

The effect of mesh density can also be seen from another point of view. With refined meshes, integration points get closer to grain boundaries, where discontinuities encourage critical values. Figure 6 exhibits this effect. Indeed, the smaller the distance to grain boundary $d_{\mathrm{GB}}$, the higher the critical values. However, the average plots show no influence of $d_{\mathrm{GB}}$, whatever mesh is used. So it can be stated that mesh density mainly affects the scattering of local variables, namely stress and plastic strain, especially near grain boundaries. Thus, in the case of a statistical analysis of local fields, mesh density should remain uniform in the whole aggregate. Otherwise, localization and scattering will be favored in the zones where the mesh is refined and the conclusions about critical zones could be biased. For these reasons, the rest of the computations were performed with the finest mesh density, homogeneous in the whole aggregate.

\subsection{Statistical analysis}

Fifteen different orientation sets have been applied to the uniaxial-y problem. Figure 7 presents the over-

\begin{tabular}{ccccc} 
Mesh & Min & Mean & Max & Std dev. \\
\hline coarse & $6.89 \mathrm{e}-07$ & $1.91 \mathrm{e}-02$ & $8.37 \mathrm{e}-02$ & $6.95 \mathrm{e}-03$ \\
medium & $0.00 \mathrm{e}+00$ & $1.89 \mathrm{e}-02$ & $1.11 \mathrm{e}-01$ & $7.28 \mathrm{e}-03$ \\
fine & $0.00 \mathrm{e}+00$ & $1.90 \mathrm{e}-02$ & $1.47 \mathrm{e}-01$ & $7.72 \mathrm{e}-03$ \\
\hline
\end{tabular}

(a) $\sum \gamma_{\text {cum }}$

\begin{tabular}{ccccc} 
Mesh & Min & Mean & Max & Std dev. \\
\hline coarse & $4.91 \mathrm{e}-07$ & $1.03 \mathrm{e}-03$ & $3.87 \mathrm{e}-03$ & $3.23 \mathrm{e}-04$ \\
medium & $0.00 \mathrm{e}+00$ & $1.04 \mathrm{e}-03$ & $5.05 \mathrm{e}-03$ & $3.62 \mathrm{e}-04$ \\
fine & $0.00 \mathrm{e}+00$ & $1.05 \mathrm{e}-03$ & $6.44 \mathrm{e}-03$ & $4.10 \mathrm{e}-04$ \\
\hline
\end{tabular}

(b) $\varepsilon_{\text {mises }}^{p}$

\begin{tabular}{ccccc} 
Mesh & Min & Mean & Max & Std dev. \\
\hline coarse & $3.79 \mathrm{e}+01$ & $1.21 \mathrm{e}+02$ & $2.39 \mathrm{e}+02$ & $2.32 \mathrm{e}+01$ \\
medium & $3.50 \mathrm{e}+01$ & $1.20 \mathrm{e}+02$ & $2.22 \mathrm{e}+02$ & $2.29 \mathrm{e}+01$ \\
fine & $2.68 \mathrm{e}+01$ & $1.21 \mathrm{e}+02$ & $2.54 \mathrm{e}+02$ & $2.32 \mathrm{e}+01$ \\
\hline
\end{tabular}

\begin{tabular}{ccccc}
\hline \multicolumn{5}{c}{$(\mathrm{c}) \sigma_{\text {mises }}[M P a]$} \\
Mesh & Min & Mean & Max & Std dev. \\
\hline coarse & $0.00 \mathrm{e}+00$ & $3.81 \mathrm{e}+00$ & $8.00 \mathrm{e}+00$ & $1.15 \mathrm{e}+00$ \\
medium & $0.00 \mathrm{e}+00$ & $3.75 \mathrm{e}+00$ & $8.00 \mathrm{e}+00$ & $1.16 \mathrm{e}+00$ \\
fine & $0.00 \mathrm{e}+00$ & $3.73 \mathrm{e}+00$ & $8.00 \mathrm{e}+00$ & $1.17 \mathrm{e}+00$ \\
\hline
\end{tabular}

(d) $N_{\gamma}$

Table 3: Statistical analysis of the distribution of local variables at Gauss points with different mesh densities.

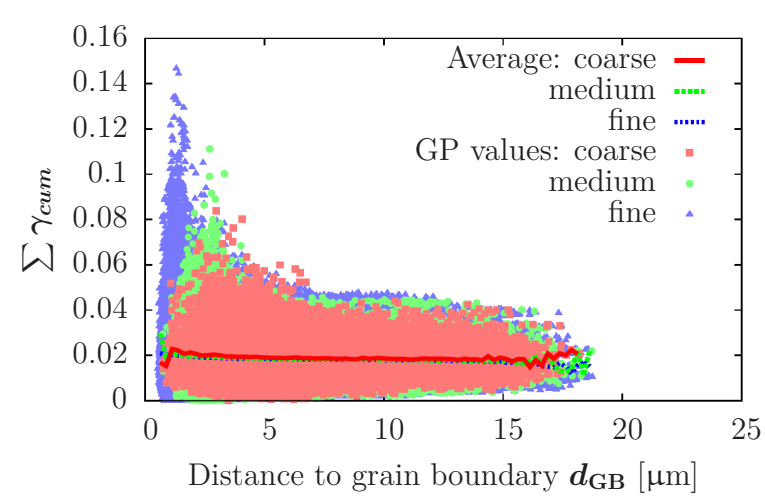

(a)

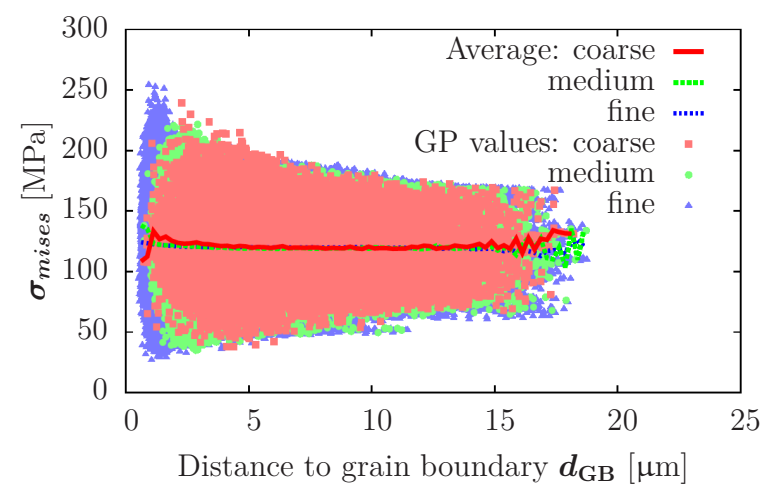

(b)

Figure 6: Values at Gauss points of some critical variables versus distance to grain boundary $d_{\mathrm{GB}}$. Discrete values (light points) and interval averages (dark lines) are both shown. 


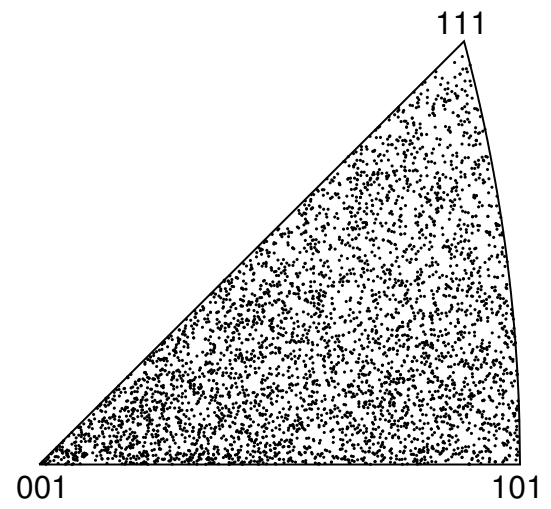

Figure 7: Inverse pole figure in $y$ direction (loading axis) of the 15 orientation sets used in the statistical analysis.

all inverse pole figure in the loading direction $(y)$ of the $15 \times 291=4365$ crystallographic orientations. This reveals no preferential texture, thus a wide range of configuration are tested with an isotropic global response. A statistical analysis is presented based on Gauss points values and grain averages.

\subsubsection{Validation of the aggregate thickness}

The aggregate used in this paper has a depth of about three grains under the free surface. To ensure the validity of such a model with the behavior inside the bulk of the material we studied the evolution along the three space axes of $\left|\sigma_{z z}\right| .\left|\sigma_{z z}\right|$ is the absolute value of the normal component of the stress on the facet perpendicular to the free surface direction. This component reveals the perturbation coming from both the free surface and the boundary condition applied at the opposite face of the aggregate, i.e. on the $z=0$ plane, where the normal displacement is set to zero. Figures $8 \mathrm{a}, 8 \mathrm{~b}$ and $8 \mathrm{c}$ present the evolution of the space average and the standard deviation of $\left|\sigma_{z z}\right|$ by small intervals along $x, y$ and $z$ axes. These plots are generated by averaging the Gauss point values in several "slices", separated by parallel planes, perpendicular to the studied axis. It clearly shows that along $x$, i.e. the direction perpendicular to both the loading direction and the free surface, and along $y$, i.e. the loading direction, $\left|\sigma_{z z}\right|$ is rather constant around $13 \mathrm{MPa}( \pm 2 \mathrm{MPa})$ with a slight increase near the boundary conditions. But along $z$ axis, $\left|\sigma_{z z}\right|$ is close to a nil value at the free surface, then increases rapidly to the same value as for $x$ and $y$ after the first layer of half-grains (around $d_{\mathrm{SURF}}=30 \mu \mathrm{m}$ ). It remains constant until the depth of $100 \mu \mathrm{m}$ where is starts to increase again until $23 \mathrm{MPa}$ at the boundary condition. In every direction, the standard deviation is mainly proportional to the average value. These observations prove that both the free surface and the boundary condition at the opposite side have a limited influence on the local mechanical fields, once the first layer of grains has been reached. Furthermore, our analysis is focused on the free surface, so a depth of three grains under the free surface is reasonable in the framework of this paper. However, next studies could be carried on with a larger amount of grains to obtain a higher fraction of grains that will be for sure considered as part of the RVE.

\subsubsection{Stress and plastic strain distributions}

Figure 9 represents the density of probability of the von Mises stress $\sigma_{\text {mises }}$, von Mises plastic strain $\varepsilon_{\text {mises }}^{p}$ and cumulated viscoplastic slip $\sum \gamma_{c u m}$ for different classes of grains (all grains, surface grains, core grains and grains at Boundary Conditions). By restricting the plot either to surface grains or to the core grains, the curves have the same shape than those obtained for all grains. The most significant effect can be seen on core grains, that present less plasticity than the rest of the grains. The maximum values are reached at the surface, thus providing a possible justification for having a preferential crack initiation at this location.

\subsubsection{Influence of Schmid factor}

Now, we focus on the grain intrinsic parameters and the influence of the neighborhood on his own mechanical response. The influence of the maximum Schmid factor $M_{\max }$ is first investigated on the variables of section 3.1 for different types of grains.

Figure 10 presents the average variables for each interval of $M_{\max }$. Whatever the type of grains (core, surface or BC grains), the curves of figure 10a (respectively 10b 10c shows a similar shape. A strong correlation appear between $M_{\max }$ and the local stress and strain state for each type of grain. However, when looking at surface grains curves, plastic strain variables depend more on the Schmid factor than the other grains: There is a weaker influence of the neighborhood for the surface grains than for others. In fact, surface grains behave more like single crystal than bulk grains due to the lower constraint at the surface. This is in good agreement with an other numerical study, previously conducted with a very simple model 34. Nevertheless, focusing on the Schmid factor only does not allow to incorporate in the discussion the influence of grain neighborhood.

\subsubsection{Influence of the misorientation}

Another parameter, the weighted misorientation $\Delta \theta_{w}^{i}$ of grain $i$, can be used as a data characterizing neighborhood. Figure 11 shows the influence of weighted misorientation $\Delta \theta_{w}$ on the investigated variables. For all types of grains, the results show a slight increase of the stress (respectively, a slight decrease of the plastic strain) for larger misorientations, as shown in figure 11a (respectively figure 11b. In addition, the viscoplastic cumulated slip is not affected by $\Delta \theta_{w}$. Therefore, it seems that all grains are not strongly affected by the weighted misorientation. Although this parameter is built from neighborhood parameters, it seems to be insufficient to characterize neighborhood effect. One may combine misorientation with Schmid factor to build a more accurate neighborhood parameter. 


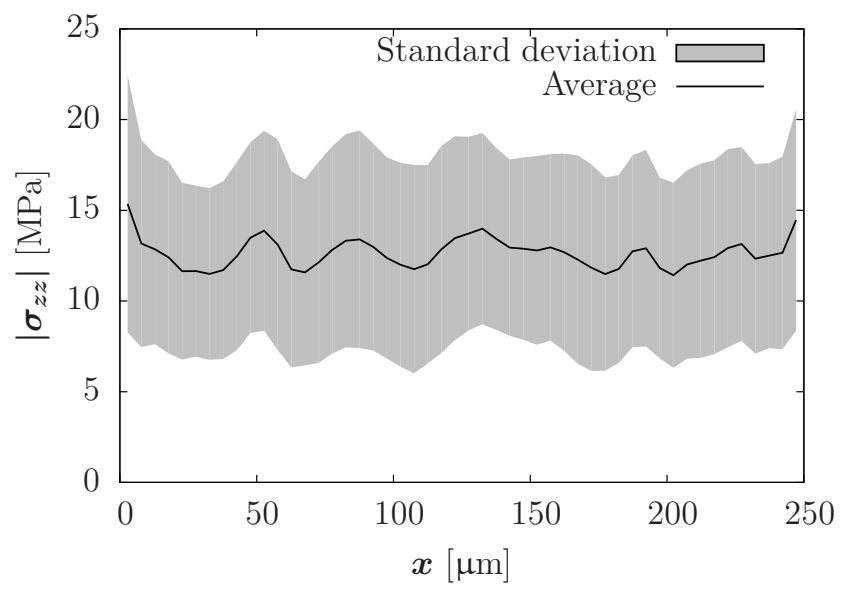

(a) Along $x$ axis

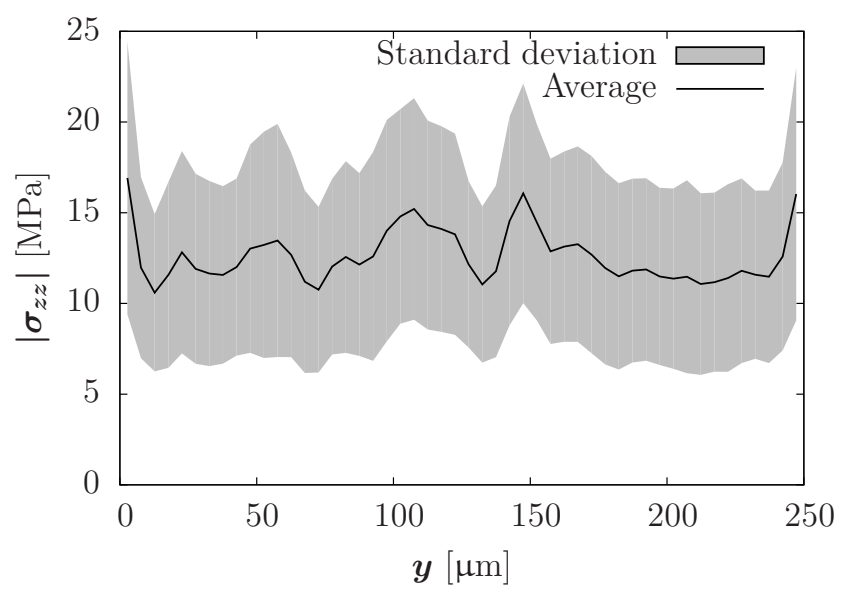

(b) Along $y$ axis

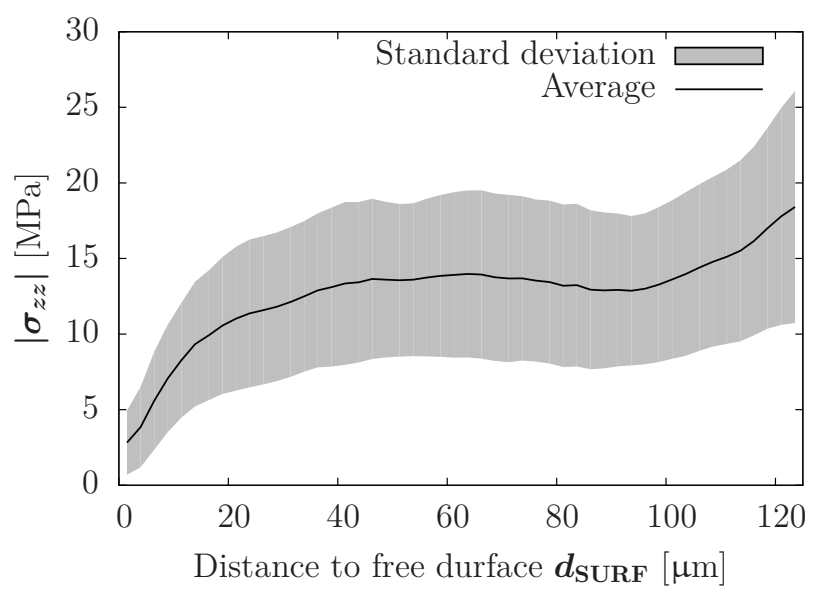

(c) Along $z$ axis, depending on the distance to the free surface.

Figure 8: Evolution of the space average and standard deviation of $\left|\sigma_{z z}\right|$ along $x, y$ and $z$ axes.

\subsection{Loading effect}

In the following, the effects of loading (uniaxial and biaxial) are studied on a single orientation set by means of three techniques. Figure 12a shows grain labels, crystallographic orientation (as a classical EBSD map) and grain boundary misorientations related to this orientation set. The thickness of the lines representing grain boundaries is related to the value of the misorientation at the frontier, the higher it is, the thicker the lines is.

\subsubsection{Surface effect}

First, the contour map of the viscoplastic cumulated slip and the equivalent plastic strain on the free surface $\mathrm{Z}$ are analyzed. Figures 13 and 14 represent the results for each loading case. The contour values of the cumulated viscoplastic slip of the aggregate show important differences depending on the loading conditions. Indeed, the localization patterns are different for the uniaxial-x loading, the uniaxial-y loading or biaxial cases. When biaxial-eq loading is applied, the response of the free surface differs qualitatively from those in both uniaxial loading cases. Obviously, this has nothing to do with a linear combination of the two uniaxial cases. In fact, the values obtained for the biaxial loading are quite higher (more than four times the maximum value obtained for uniaxial loading). The map obtained with the equivalent von Mises plastic strain, in figure 14. looks like the cumulated viscoplastic strain map, figure 13 For biaxial-eq loading, the values are higher than for uniaxial loading and the morphology differs from the uniaxial case. The disparity of the results is mainly due to the activation of different slip systems which depends on the loading direction. Indeed, for a given grain orientation, a load in direction $x, y$ or both, does not activate the same slip systems.

Figure 15 shows the contour maps of the von Mises stress $\sigma_{m i s e s}$ on the free surface. It generally exhibits contrasted values on each side of the grain boundaries. Comparing with figures 13 and 14 , we can also notice that due to the crystal plasticity model, there is no complete correlation between stress and plastic strain localization.

To complete the study, the number of active slip systems $N_{\gamma}$ is investigated for each loading, figure 16. In the same aggregate, the number of active slip systems depends on the loading type. For example, for uniaxial-x loading, a grain can have three active slip systems when six are active for uniaxial-y loading, and conversely (see for example, the grains 259 and 274). In both biaxial and biaxial-eq cases, the distribution of $N_{\gamma}$ seems very similar, so it is weakly affected by loading amplitude. From a global point of view, biaxial loadings, even with the same equivalent deformation, lead to a larger number of grains with more active slip systems, if compared to uniaxial loading (see for example, the grains 258, 276 and 291).

In conclusion, through the results of figures 13, 14, 15 and 16, we can conclude that the free surface response remains closely related to the crystallographic orientation. 


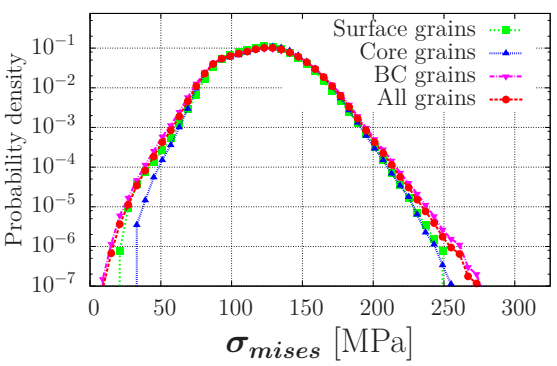

(a)

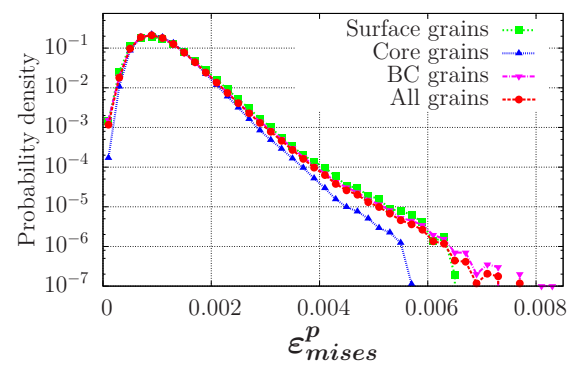

(b)

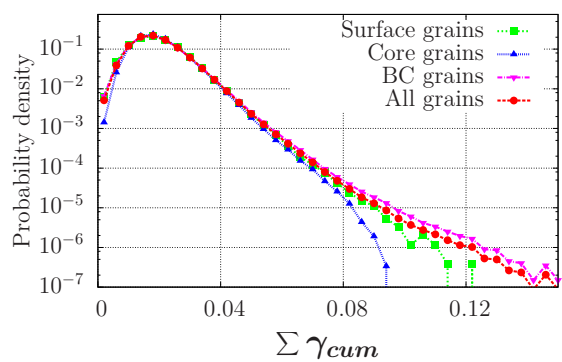

(c)

Figure 9: Density of probability of (a) $\sigma_{\text {mises }}$, (b) $\varepsilon_{\text {mises }}^{p}$ and (c) $\sum \gamma_{c u m}$ for different types of grains.

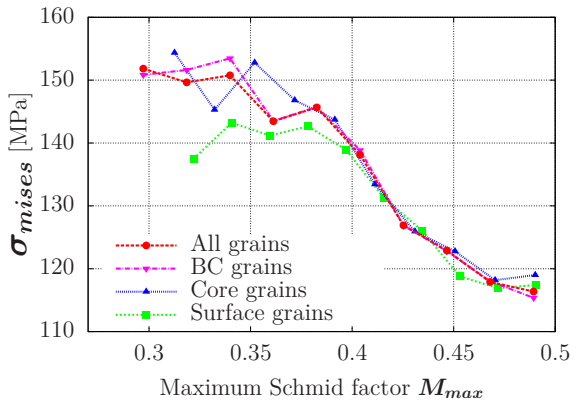

(a)

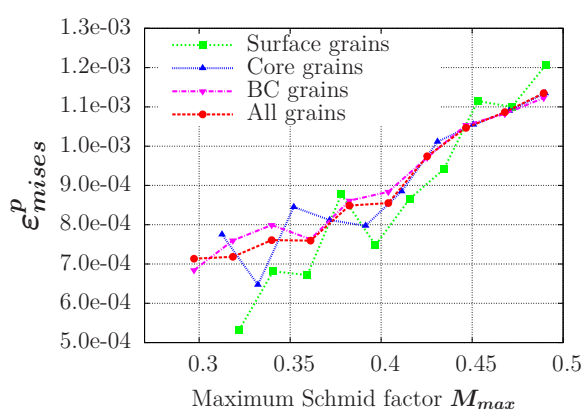

(b)

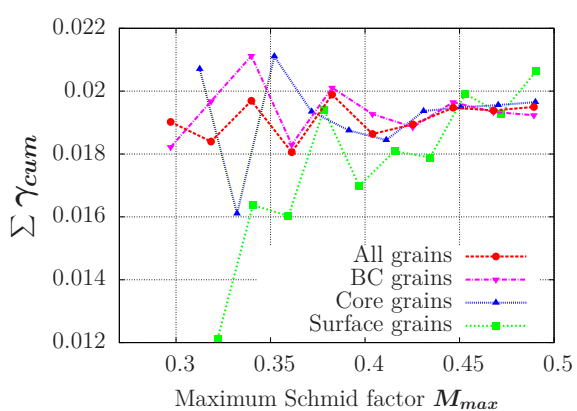

(c)

Figure 10: Influence of the Schmid factor $M_{\max }$ on (a) $\sigma_{\text {mises }}$ (b) $\varepsilon_{\text {mises }}^{p}$ and (c) $\sum \gamma_{\text {cum }}$ for different types of grains.

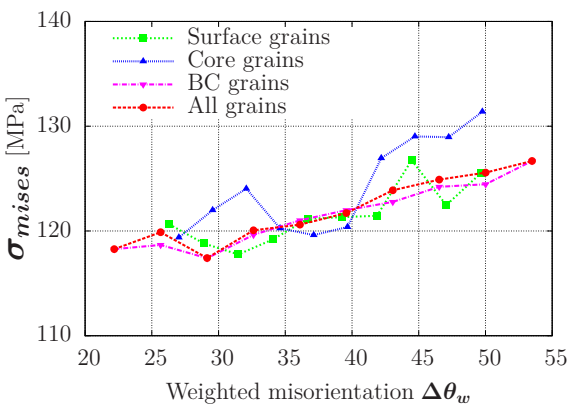

(a)

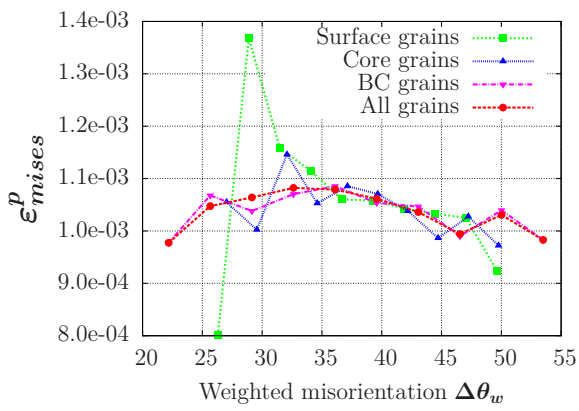

(b)

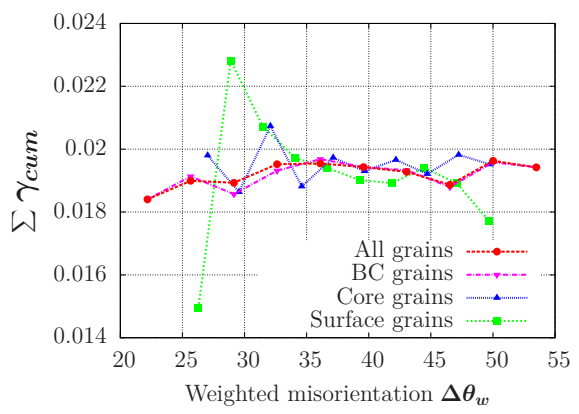

(c)

Figure 11: Influence of weighted misorientation $\Delta \theta_{w}$ on (a) $\sigma_{\text {mises }}$ (b) $\varepsilon_{\text {mises }}^{p}$ and (c) $\sum \gamma_{c u m}$ for different types of grains. 


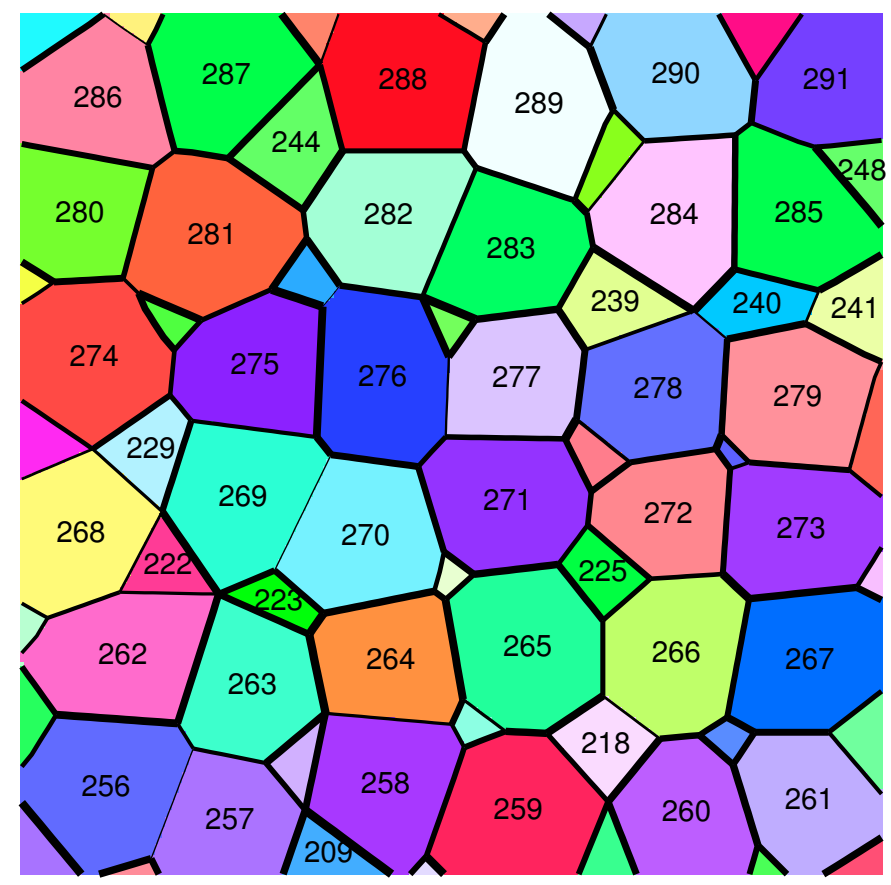

(a)

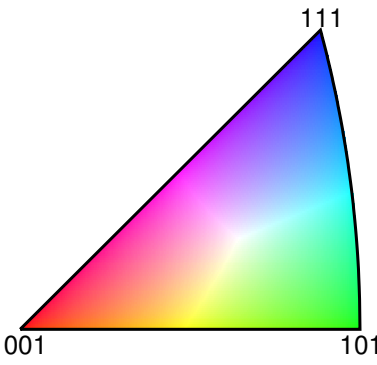

(b)

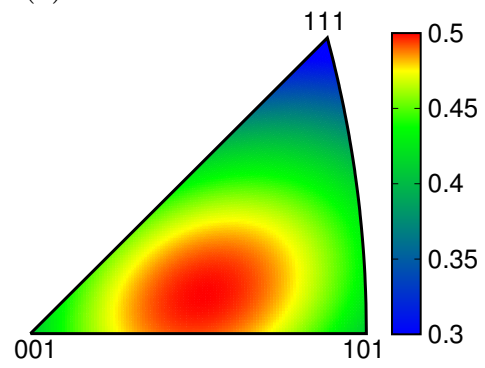

(c)
Figure 12: Description of the studied orientation set at the free surface. (a) Grain labels, EBSD map and misorientation between grains described by the thickness of lines. (b) Orientation color code in standard stereo-triangle. (c) Maximal Schmid factor in standard stereo-triangle.

Table 4 sums up various observations carried out at grain boundaries on figure 13, 14, 15 and 16. Specific orientation and misorientation configuration are presented. For instance, grain boundaries with both low and high misorientations are studied. Moreover, various angle configurations (angle between the loading axis and the grain boundary $\left.\theta_{\mathrm{GB} / \mathrm{load}}\right)$ are also shown.

Plastic flow is enhanced at grain boundaries (grains $287 / 244$, grains $289 / 290$, grains $218 / 266$ ). This can be the consequence of a strong misorientation (grains 287/244, grains 289/290) but it may also happen with a lower misorientation (grains 218/266). Thus, a strong misorientation does not always produce a localization (grains $275 / 276$ ) and, low misorientations can even produce a plastic strain localization (grains 218/226). The angle between the loading axis and the grain boundary $\theta_{\mathrm{GB} / \text { load }}$ is not a key factor: strong localization can be present with various values of $\theta_{\mathrm{GB} / \text { load }}\left(18^{\circ}\right.$ for the grains $289 / 290$, about $45^{\circ}$ for the grains $244 / 287$ or $218 / 266,72^{\circ}$ for the grains $289 / 290)$. Moreover, according to the loading conditions, there can be high or low localization at some grain boundaries (grains 244/287: uniaxial-y, uniaxial-x, grains 218/266: uniaxial-x, uniaxial-y) whether the crystallographic misorientation is high or low.

\subsubsection{Strain localization in the bulk}

A new visualization technique has been developed to characterize the deformation state in the bulk of the aggregate. It consists in transparent volumetric views, revealing the spatial organization of local fields in the volume. These views have been generated using the opacity filter from the graphical post-processing tool Salome [35, which is an open-source Pre- and Post-Processing software. Viscoplastic cumulated slip isosurfaces are illustrated in figure 18 for uniaxial-x, uniaxial-y and biaxial-eq loadings. The different parts of the figures correspond to snapshots taken from the three space directions. Referring to the classical A and $\mathrm{B}$ facets 1, illustrated in figure 17, experimental studies showed that uniaxial cyclic loadings lead to mixed A/B facets and biaxial loadings cause mostly $\mathrm{B}$ facets which are more damaging for the material. Figure $18 \mathrm{~b}$, referring to uniaxial-x case, shows localization bands oriented at $45^{\circ}$ with respect to loading direction, in snapshots taken from the top ( $y$ direction) and from the front ( $z$ direction) which is the free surface direction. More specifically, in the view from the top, these bands are emerging from the free surface like B facets. In the $z$ direction, a surface "shear" and the component absence along the direction of the free surface are highlighted like A facets. Respectively figure 18b, referring to uniaxial-y case, shows the same patterns, seen from the right ( $x$ direction) and from the front ( $z$ direction). Table 5 summarizes the identified localization bands patterns. In contrast, figure $18 \mathrm{c}$ reveals localization bands at $45^{\circ}$ in $x$ and $y$ directions. In both $x$ and $y$ views, the bands have a component in the direction of the free surface, such as B facets. Therefore, this phenomenon involves more formation of intrusion/extrusion. Thus, we can conclude with a higher vulnerability, and an early microcrack initiation, in the case of biaxial loading. These global views prove a good agreement with previous experimental [36, 37] and numerical studies 38].

\subsubsection{Surface slip marking indicators}

The last analysis on the free surface behavior is obtained through a parameter providing information on the intrusion/extrusion mechanism. An estimation of the possible step height and orientation is obtained by drawing color lines, the orientation of which is determined by the surface trace of the plane $\underline{\boldsymbol{l}}_{\text {surf }}$ and the color by the intensity of $\gamma_{\text {surf }}$. Figure 19 shows the results obtained for all loading cases. For a given grain (e.g. grains 266, 276 or 291), a change of loading direction involves a change in direction and intensity of the steps, figure 19a and 19b. For the biaxial load, the intensity is higher than for the uniaxial case, (e.g. grains 263, 264 or 273). The maximum 


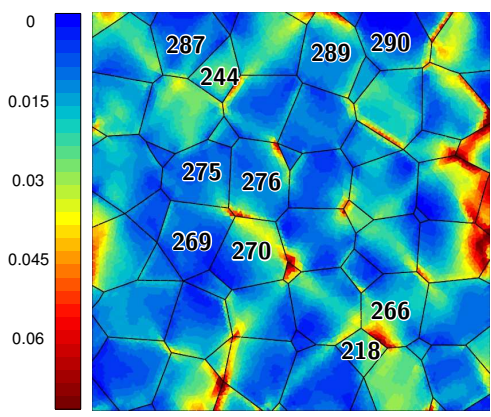

(a) Uniaxial-x

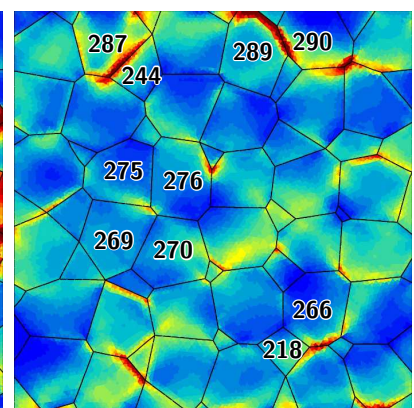

(b) Uniaxial-y

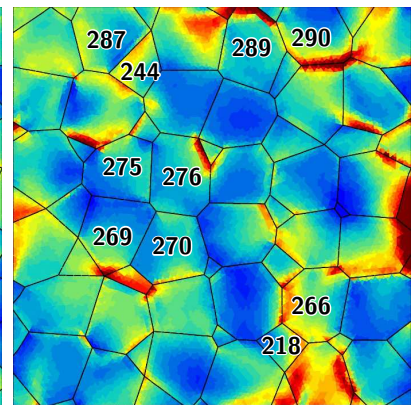

(c) Biaxial-eq

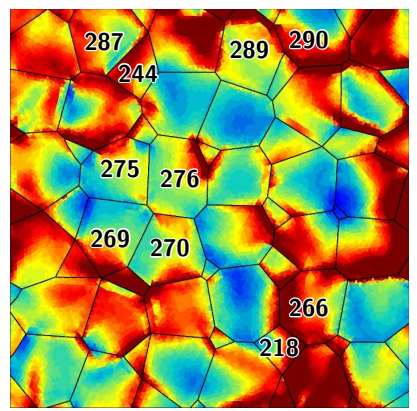

(d) Biaxial

Figure 13: $\sum \gamma_{\text {cum }}$ free surface $\mathrm{Z}$ map for each loading case.

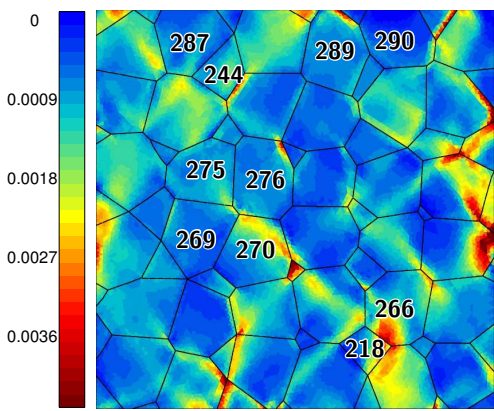

(a) Uniaxial-x

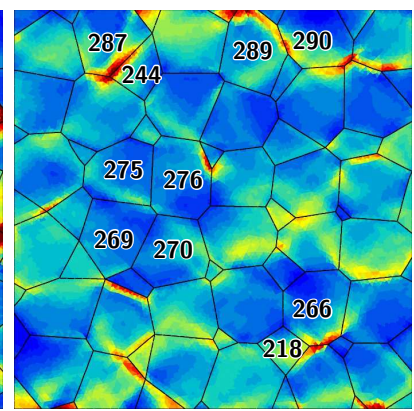

(b) Uniaxial-y

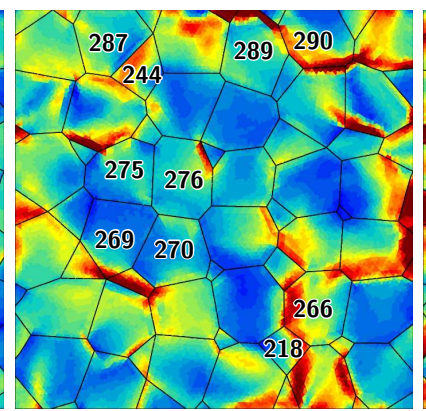

(c) Biaxial-eq

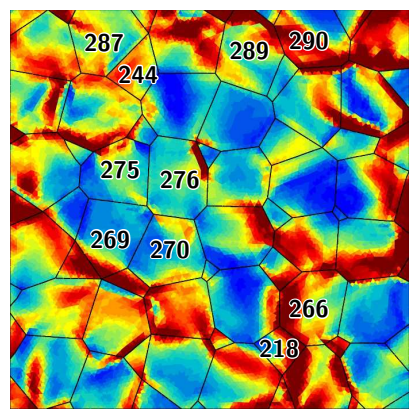

(d) Biaxial

Figure 14: $\varepsilon_{\text {mises }}^{p}$ free surface $\mathrm{Z}$ map for each loading case.

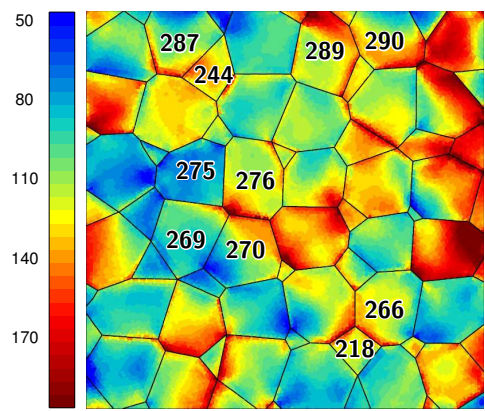

(a) Uniaxial-x

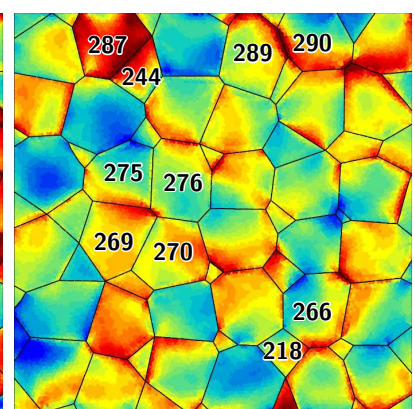

(b) Uniaxial-y

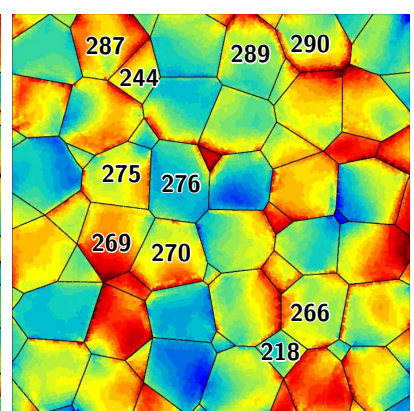

(c) Biaxial-eq

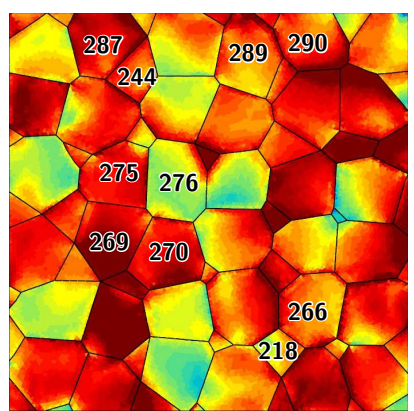

(d) Biaxial

Figure 15: $\sigma_{\text {mises }}$ free surface $\mathrm{Z}$ map for each loading case [MPa].

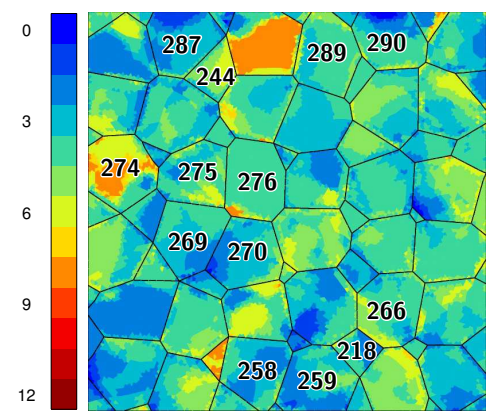

(a) Uniaxial-x

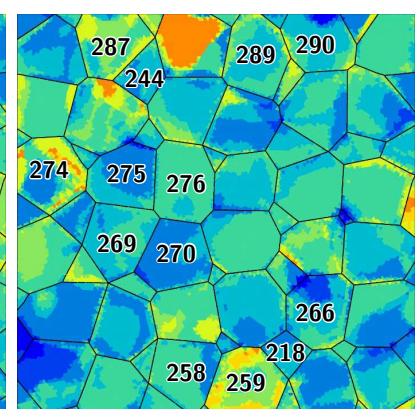

(b) Uniaxial-y

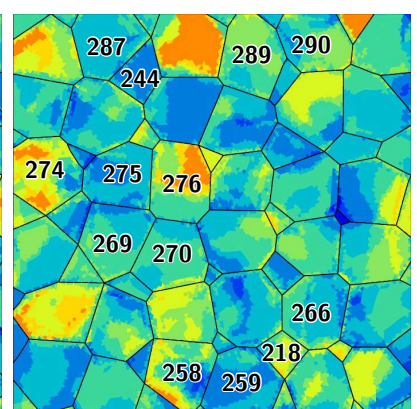

(c) Biaxial-eq

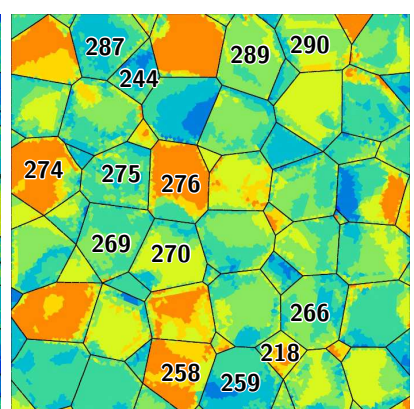

(d) Biaxial

Figure 16: $N_{\gamma}$ free surface Z map for each loading case. 


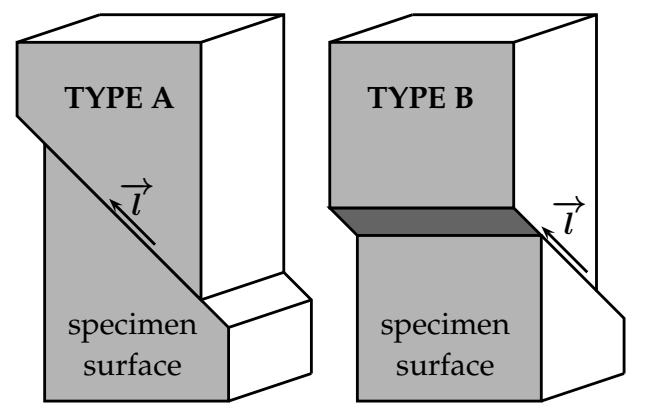

Figure 17: Facets of type A and B, according to Miller [1].

intensity is often reached near grain boundaries where additional slip systems are activated due to local stress deviation (e.g. grains 273, 278, 286 or 291). On the other hand, if we focus our attention on the interior of a particular grain, there is mainly one or two active planes. The results are in agreement with experiments [39. This parameter allows to show a little influence of the surface grain neighborhood. But it also reinforces the results previously obtained regarding crystal orientation.

\section{Conclusion}

The main purpose of the paper was to study the consequences of the loading on the free surface response in polycrystalline aggregates, using Finite Element Crystal Plasticity. First, a statistical analysis is carried out to study the local strain and stress fields at the free surface and extract information on the neighborhood effect. The influence of the Schmid factor and the weighted misorientation have been studied on various variables: the equivalent von Mises stress, the von Mises equivalent plastic strain and the sum of cumulated viscoplastic slip. It seems that these factors are insufficient to characterize neighborhood effect. Then, different innovative tools were used to analyze the effects of free surface on local mechanical fields: surface contour maps, transparent volumetric views, a parameter characterizing the extrusion/intrusion surface steps. The response depends on the loading and seems strongly influenced by the crystallographic orientation of the grains. The benefit of the transparent volumetric views must be emphasized. This new visualization technique allowed us to highlight the plastic strain localization patterns inside the bulk. The results obtained are in agreement with experimental results: mixed A/B facets for uniaxial loadings, mostly B facets for biaxial loadings.

While using the same single crystal model for surface and core grains, in the framework of classical continuum mechanics, that is without any specific gradient type effect, the numerical results show that surface grains behave more like its single crystal counterpart than core grains. Indeed, plastic slip activity in surface grains depends strongly on the Schmid factor. Surrounding grains are more involved in the neighboring effect when they are located inside the core. Studying consequences of strain localization at the free surface and inside the volume of the polycrystal revealed a harmful impact of biaxial loading compared to uniaxial loading. Local aspect of PSM can hardly be described with actual mesh density, but gives relevant information about their intensity and orientation. However, better information on surface grains and the induced relief could be provided by Discrete Dislocation Dynamics coupled with FE. Some improvement could be provided to the model identification by combining macro and grain scale identification. This can be achieved using local strain tensors measurements through the brand new DCT analysis techniques, which is a real challenge for both experimental and numerical studies of polycrystals.

\section{Acknowledgement}

The work has been supported by Agence Nationale pour la Recherche, in the framework of the project AFGRAP.

[1] K. Miller, The behaviour of short fatigue cracks and their initiation. Part II-A General summary, Fatigue and Fracture of Engng Mat and Struct 10 (1987) 93-113.

[2] P. Forsyth, C. Stubbington, The structure of slip band extrusion revealed by transmission electron microscopy, Acta Metall. 8 (1960) 811-814

[3] U. Essmann, U. Gösele, H. Mughrabi, A model of extrusions and intrusions in fatigued metals: I. Point-defect production and the growth of extrusions, Phil. Mag. 44 (1981) 405-426.

[4] B.-T. Ma, C. Laird, Overview of fatigue behavior in copper single crystals: I. Surface morphology and stage I crack initiation sites for tests at constant strain amplitude, Acta Mat. 37 (1989) 325-336.

[5] C. Blochwitz, J. Brechbühl, W. Tirschler, Analysis of activated slip systems in fatigue nickel polycrystals using the EBSDtechnique in the scanning electron microscope, Mater. Sci. Eng. A210 (1996) 42-47.

[6] J. Man, K. Ortblík, J. Polák, Study of surface relief evolution in fatigued 316L austenitic stainless steel by AFM, Mater. Sci. Eng. A351 (2003) 123-132.

[7] C. Déprés, C. Robertson, M. Fivel, Low-strain fatigue in 316L steel surface grains: a three dimension discrete dislocation dynamics modelling of the early cycles. Part 2: Persistent slip markings and micro-crack nucleation, Phil. Mag. 86 (1) (2006) 79-97.

[8] F. Dunne, A. Wilkinson, R. Allen, Experimental and computational studies of low cycle fatigue crack nucleation in a polycrystal, Int. J. of Plasticity 23 (2007) 273-295.

[9] M. Zhang, F. Bridier, P. Villechaise, J. Mendez, D. McDowell, Simulation of slip band evolution in duplex Ti-6Al-4V, Acta Mat. 58 (2010) 1087-1096.

[10] M. Sauzay, P. Gilormini, Influence of surface effects on fatigue of microcracks nucleation, Theoretical and Applied Fracture Mechanics 38 (2002) 53-62.

[11] F. Barbe, S. Forest, G. Cailletaud, Intergranular and intragranular behavior of polycrystalline aggregates. Part II: Results, Int. J. of Plasticity 17 (4) (2001) 537-563.

[12] C. Przybyla, D. McDowell, Microstructure-sensitive extreme value probabilities for high cycle fatigue of $\mathrm{Ni}$-base superalloy IN100, Int. J. of Plasticity 26 (2010) 372-394.

[13] L. Méric, G. Cailletaud, Single crystal modeling for structural calculations. Part 2: Finite element implementation, J. of Engng. Mat. Technol. 113 (1991) 171-182.

[14] J. Besson, G. Cailletaud, J.-L. Chaboche, S. Forest, Nonlinear Mechanics of Materials, Springer, 2009.

[15] P. Franciosi, The concepts of latent hardening and strain hardening in metallic single crystals, Acta Metall. 33 (1985) 16011612 . 


\begin{tabular}{|c|c|c|c|c|}
\hline Grains & $\Delta \theta$ & Loading & $\theta_{\mathrm{GB} / \mathrm{load}}$ & Observations \\
\hline \multirow[t]{4}{*}{$275 / 276$} & \multirow[t]{4}{*}{$\begin{array}{l}55.4^{\circ} \\
\text { (high) }\end{array}$} & uniaxial-x & $87^{\circ}$ & $\begin{array}{l}\text { No localization for } \sum \gamma_{c u m} \text { and } \varepsilon_{\text {mises }}^{p}, \\
\text { contrasted values for } \sigma_{\text {mises }}\end{array}$ \\
\hline & & uniaxial-y & $3^{\circ}$ & No localization for $\sum \gamma_{c u m}$ and $\varepsilon_{\text {mises }}^{p}$ \\
\hline & & biaxial-eq & $3^{\circ} / 87^{\circ}$ & $\begin{array}{l}\text { Very light localization for } \sum \gamma_{c u m} \text { and } \varepsilon_{\text {mises }}^{p} \text {, } \\
\text { contrasted values for } \sigma_{\text {mises }} \text { and } N_{\gamma}\end{array}$ \\
\hline & & biaxial & $3^{\circ} / 87^{\circ}$ & $\begin{array}{l}\text { Light localization for } \sum \gamma_{c u m} \text { and } \varepsilon_{\text {mises }}^{p} \\
\text { highly contrasted values for } \sigma_{\text {mises }} \text { and } N_{\gamma}\end{array}$ \\
\hline \multirow[t]{3}{*}{$244 / 287$} & \multirow[t]{3}{*}{$\begin{array}{l}47.8^{\circ} \\
\text { (high) }\end{array}$} & uniaxial-x & $46^{\circ}$ & $\begin{array}{l}\text { No localization for } \sum \gamma_{c u m} \text { and } \varepsilon_{\text {mises }}^{p} \text {, } \\
\text { light localization for } \sigma_{m i s e s} \text {, contrasted values for } N_{\gamma}\end{array}$ \\
\hline & & uniaxial-y & $44^{\circ}$ & $\begin{array}{l}\text { Strong localization for } \sum \gamma_{c u m} \text { and } \varepsilon_{\text {mises }}^{p} \\
\text { high values for } \sigma_{\text {mises }} \text {, contrasted values for } N_{\gamma}\end{array}$ \\
\hline & & biaxial(-eq) & $46^{\circ} / 44^{\circ}$ & Localization and contrasted values for $\sum \gamma_{c u m}$ and $\varepsilon_{\text {mises }}^{p}$ \\
\hline \multirow[t]{3}{*}{$289 / 290$} & \multirow[t]{3}{*}{$\begin{array}{l}53.4^{\circ} \\
(\text { high })\end{array}$} & uniaxial-x & $72^{\circ}$ & No localization for $\sum \gamma_{c u m}$ and $\varepsilon_{m i s e s}^{p}$ \\
\hline & & uniaxial-y & $18^{\circ}$ & Strong localization for $\sum \gamma_{c u m}, \varepsilon_{\text {mises }}^{p}$ and $\sigma_{\text {mises }}$ \\
\hline & & biaxial(-eq) & $72^{\circ} / 18^{\circ}$ & Strong localization for $\sum \gamma_{\text {cum }}$ and $\varepsilon_{\text {mises }}^{p}$ \\
\hline \multirow[t]{3}{*}{$218 / 266$} & \multirow[t]{3}{*}{$\begin{array}{l}21.0^{\circ} \\
(\text { low })\end{array}$} & uniaxial-x & $36^{\circ}$ & $\begin{array}{l}\text { Localization for } \sum \gamma_{c u m} \text { and } \varepsilon_{\text {mises }}^{p} \\
\text { contrasted values for } \sigma_{\text {mises }} \text { and } N_{\gamma}\end{array}$ \\
\hline & & uniaxial-y & $54^{\circ}$ & Light localization for $\varepsilon_{\text {mises }}^{p}$ \\
\hline & & biaxial(-eq) & $36^{\circ} / 54^{\circ}$ & $\begin{array}{l}\text { Strong localization for } \sum \gamma_{c u m} \text { and } \varepsilon_{\text {mises }}^{p} \text {, } \\
\text { contrasted values for } \sigma_{\text {mises }} \text { and } N_{\gamma}\end{array}$ \\
\hline $269 / 270$ & $\begin{array}{l}11.1^{\circ} \\
\text { (low) }\end{array}$ & all & $26^{\circ} / 64^{\circ}$ & No localization for $\sum \gamma_{c u m}$ and $\varepsilon_{m i s e s}^{p}$ \\
\hline
\end{tabular}

Table 4: Description of the localization of local variables at typical grain boundaries accounting for orientation and misorientation parameters.

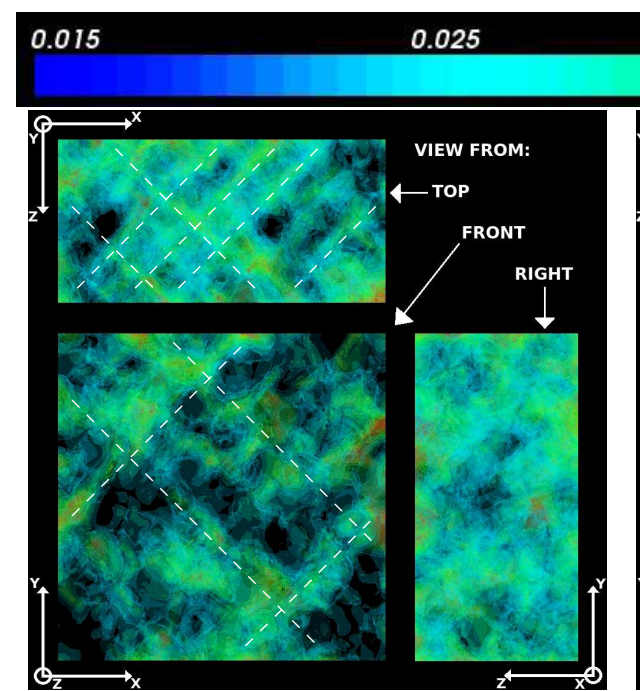

(a) Uniaxial-x

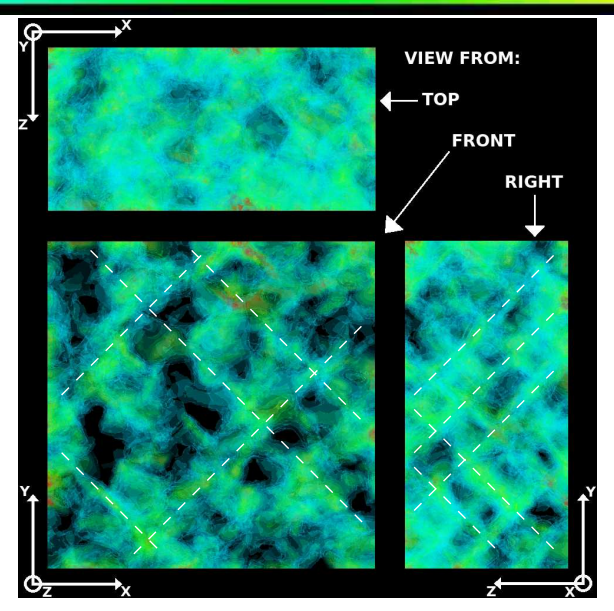

(b) Uniaxial-y
0.045

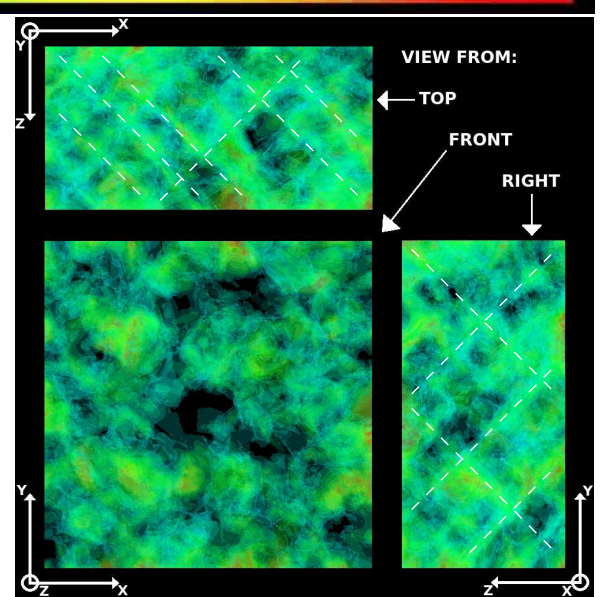

(c) Biaxial-eq

Figure 18: Transparent volumetric views of $\sum \gamma_{c u m}$ in each space direction for the three loading cases. 


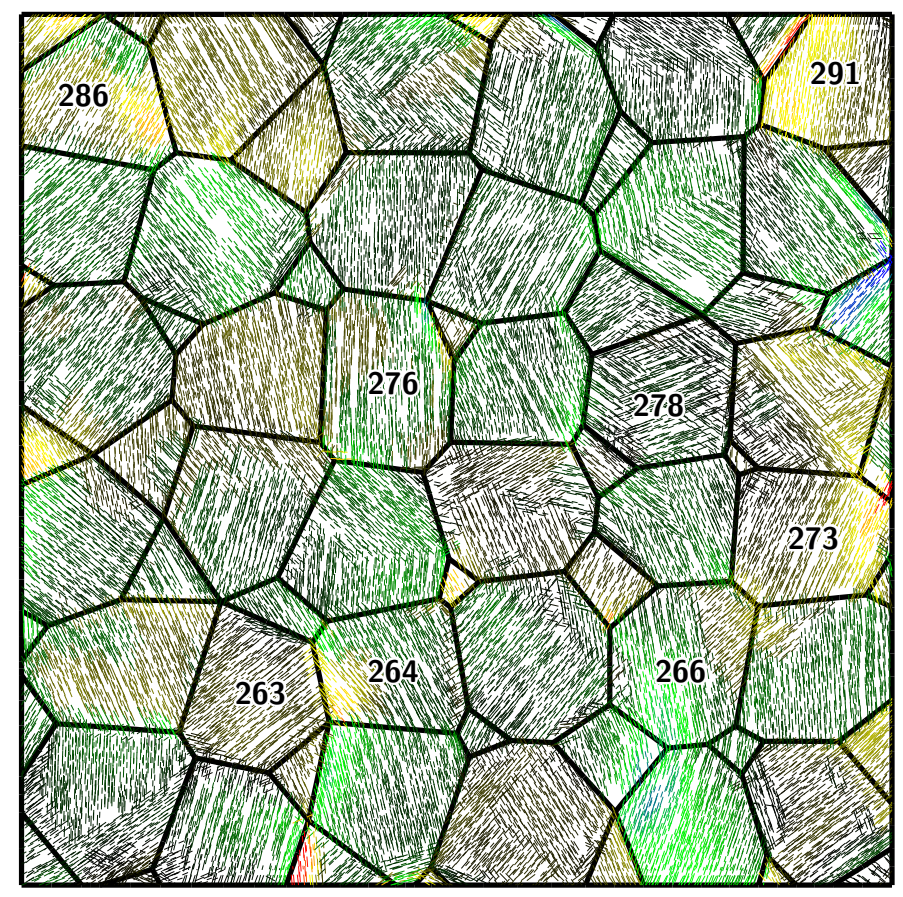

(a) Uniaxial-x

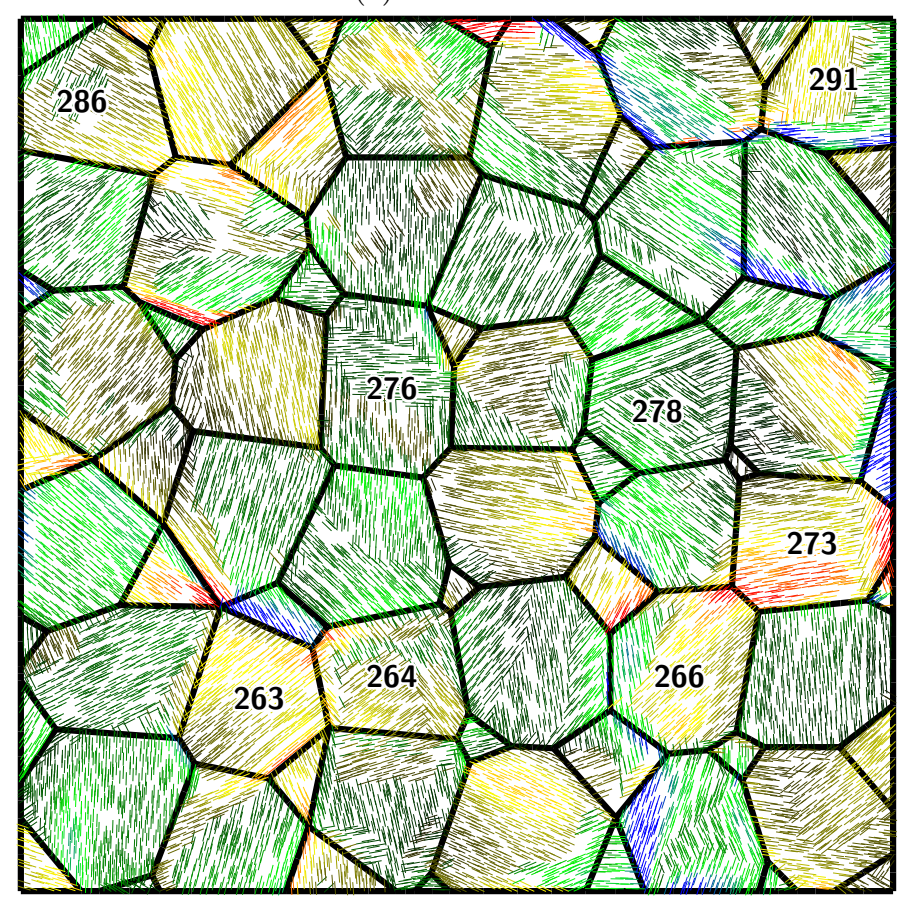

(c) Biaxial-eq

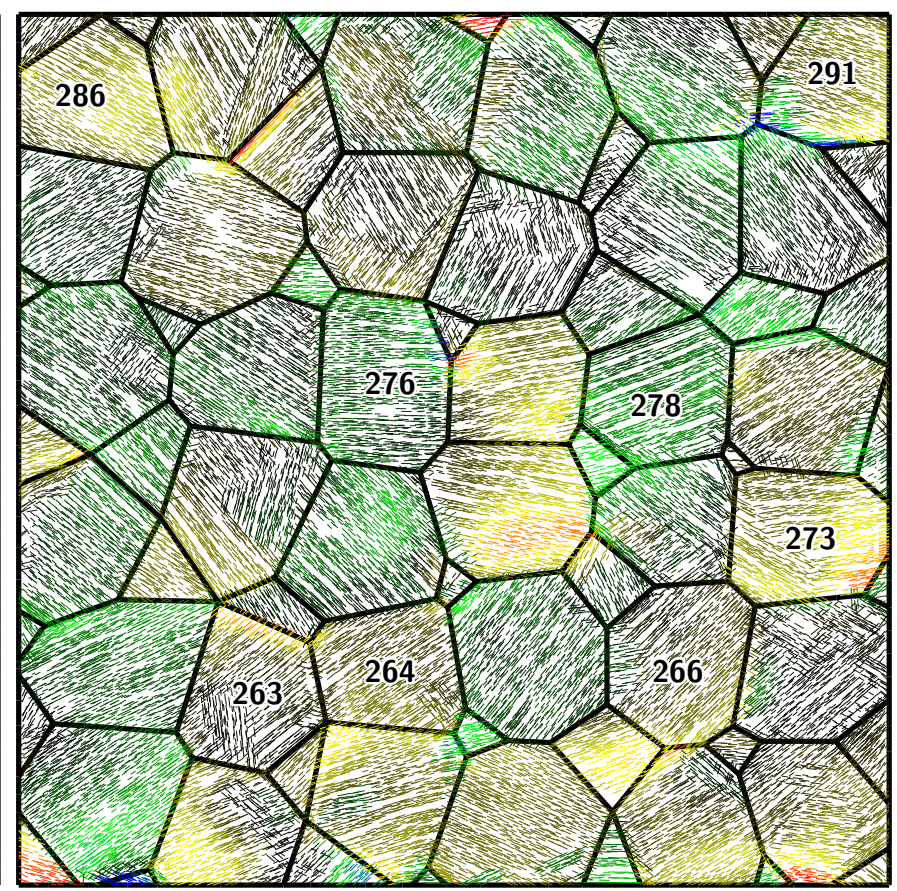

(b) Uniaxial-y

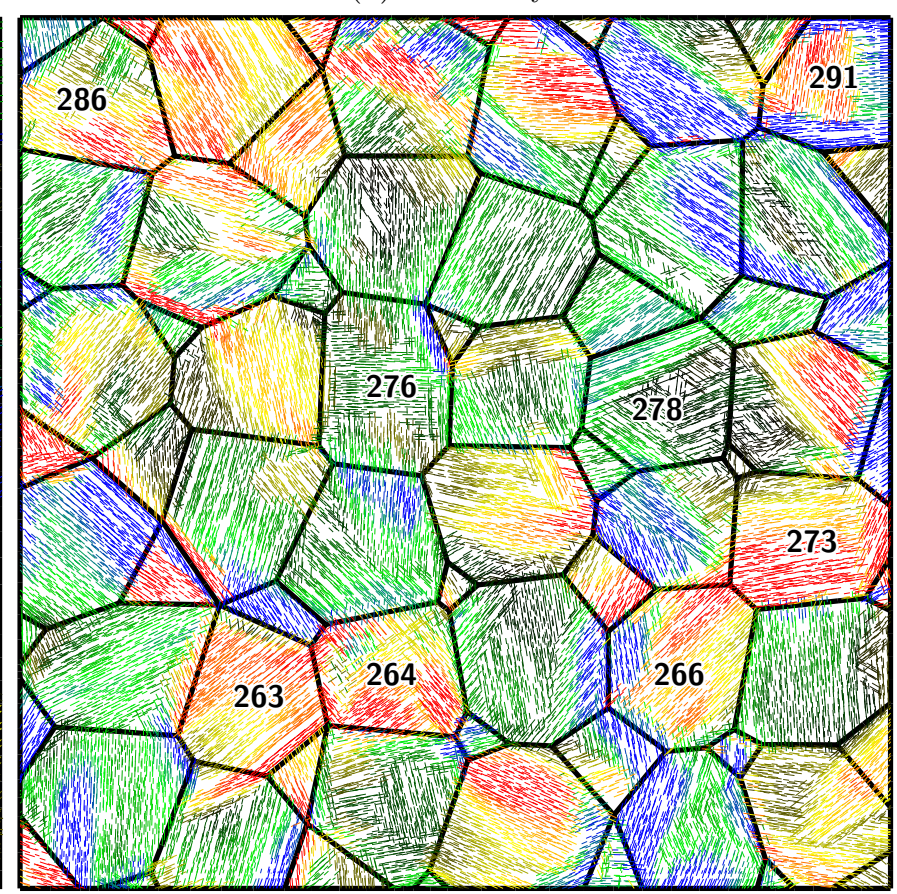

(d) Biaxial

$\max / 5$

Figure 19: Surface intrusion/extrusion indicator orientation and intensity for each loading case. 


\begin{tabular}{|c|c|c|c|c|}
\hline \multirow{2}{*}{ Load } & \multicolumn{3}{|c|}{$45^{\circ}$ bands in direction } & \multirow{2}{*}{ Facets } \\
\hline & $x$ & $y$ & $z$ & \\
\hline Uniaxial-x & & $*$ & $*$ & $\mathrm{~A}+\mathrm{B}$ \\
\hline Uniaxial-y & $*$ & & $*$ & $\mathrm{~A}+\mathrm{B}$ \\
\hline Biaxial-eq & * & $*$ & & $\mathrm{~B}$ \\
\hline
\end{tabular}

Table 5: Plastic localization patterns and facets type in each loading case.

[16] H. Huntington, The elastic constants of crystals, Solid State Physics 7 (1958) 213-351.

[17] J. Eshelby, The determination of the elastic field of an ellipsoidal inclusion, and related problems, Proc. Royal Soc. London 241 (1957) 376-396.

[18] R. Hill, Continuum micro-mechanisms of elastoplastic polycrystals, J. Mech. Phys. Sol. 13 (1965) 89-101.

[19] M. Berveiller, A. Zaoui, An extension of the self-consistent scheme to plastically flowing polycrystal, J. Mech. Phys. Sol. 26 (1979) 325-344.

[20] G. Cailletaud, P. Pilvin, Utilisation de modèles polycristallins pour le calcul par éléments finis, Revue Européenne des Éléments Finis 3 (4) (1994) 515-541.

[21] D. Barreau, Essais de fatigue dans l'air de deux nuances d'aciers inoxydables, Tech. Rep. S-99/5319000, Centre d'essais aéronautique de Toulouse, contrat EDF (2000).

[22] C. Gérard, B. Bacroix, M. Bornert, G. Cailletaud, J. Crépin, S. Leclercq, Hardening description for FCC materials under complex loading paths, Computational Materials Science 45 (2009) 751-755.

[23] S. Queyreau, G. Monnet, B. Devincre, Slip systems interactions in $\alpha$-iron determined by dislocation dynamics simulations, Int. J. of Plasticity 25 (2009) 361-377.

[24] W. Ludwig, A. King, P. Reischig, H. M., E. Lauridsen, S. Schmidt, H. Proudhon, S. Forest, P. Cloetens, S. Rolland du Roscoat, J. Buffière, T. Marrow, H. Poulsen, New opportunities for $3 \mathrm{~d}$ materials science of polycrystalline materials at the micrometre lengthscale by combined use of x-ray diffraction and x-ray imaging, Mater. Sci. Eng. A 524 (1-2) (2009) 69-76.

[25] M. Herbig, A. King, P. Reischig, H. Proudhon, E. Lauridsen, J. Marrow, J.-Y. Buffière, W. Ludwig, 3-D growth of a short fatigue crack within a polycrystalline microstructure studied using combined diffraction and phase-contrast X-ray tomography, Acta Mat. 59 (2011) 590-601.

[26] J. Oddershede, S. Schmidt, H. F. Poulsen, O. Sørensen, J. Wright, W. Reimers, Determining grain resolved stresses in polycrystalline materials using three-dimensional x-ray diffraction, JAC 43 (2010) 539-549.

[27] P. Reischig, Determination of elastic strain tensors from X-ray diffraction contrast tomography, Master's thesis, Delft University of Technology (2008).

[28] P. Reischig, A. King, L. Nervo, N. Viganó, Y. Guilhem, W. Palenstijn, K. Batenburg, M. Preuss, W. Ludwig, Advances in X-ray diffraction tomography: Flexibility in the setup geometry and application to multiphase materials, J. Appl. Cryst.Accepted.

[29] F. Barbe, L. Decker, D. Jeulin, G. Cailletaud, Intergranular and intragranular behavior of polycrystalline aggregates. Part I: FE model, Int. J. of Plasticity 17 (4) (2001) 513-536.

[30] C. Farhat, F.-X. Roux, Implicit parallel processing in structural mechanics, Computational Mechanics Advances 2 (1) (1994) 1124.

[31] I. Gueye, S. El Arem, F. Feyel, F.-X. Roux, G. Cailletaud, A new parallel sparse direct solver : presentation and numerical experiments in large-scale structural mechanics parallel computing, Int. J. Numer. Meth. Engng 88 (2011) 370-384.

[32] E. Héripré, M. Dexet, J. Crépin, L. Gélébart, A. Roos, M. Bornert, D. Caldemaison, Coupling between experimental measurements and polycrystal finite element calculations for micromechanical study of metallic materials, Int. J. of Plasticity
23 (2007) 1512-1539.

[33] V. Randle, Microtexture Determination and its Applications, The Institute of Materials, 1992.

[34] Y. Guilhem, S. Basseville, F. Curtit, J.-M. Stéphan, G. Cailletaud, Investigation of the effect of grain clusters on fatigue crack initiation in polycrystals, Int. J. Fatigue 32 (2010) 17481763.

[35] Salome, http://www.salome-platform.org version 5.1 (2008).

[36] M. Brown, K. Miller, Initiation and growth of cracks in biaxial fatigue, Fatigue and Fracture of Engng Mat and Struct 1 (1979) 231-246.

[37] V. Doquet, Crack initiation mechanisms in torsional fatigue, Fatigue and Fracture of Engng Mat and Struct 20 (2) (1997) $227-235$.

[38] M. Sauzay, P. Gilormini, Surface and cyclic microplasticity, Fatigue and Fracture of Engng Mat and Struct 23 (2000) 573-579.

[39] J. Schwartz, O. Fandeur, C. Rey, Fatigue crack initiation modeling of 316LN steel based on non local plasticity theory, Procedia Engineering 2 (2010) 1353-1362. 